\title{
Strategies of Sexual Reproduction in Aphids
}

\author{
Dissertation \\ zur Erlangung des Doktorgrades \\ der Mathematisch-Naturwissenschaftlichen Fakultäten \\ der Georg-August-Universität zu Göttingen
}

vorgelegt von

Joachim Dagg

aus Frankfurt am Main

Göttingen 2002 
D 7

Referent: Prof. Dr. Schaefer

Korreferent: Prof. Dr. Ehlers

Tag der Mündlichen Prüfung: 30.10.2002 
Für meinen Vater Dietmar Dagg $(* 2.10 .1942, \nmid 23.7 .1997)$ 


\section{Acknowledgements}

My visit at the University of East Anglia in Norwich was funded by the Deutscher Akademischer Austausch Dienst. I thank Prof. Anthony F. G. Dixon for excellent support and supervision in Norwich and Prof. Stefan Vidal for the same in Göttingen.

Further thanks go to: Prof. Matthias Schaefer for yielding the theme to me; Thomas Thieme for a tip on preparing the sperm storage organ of female aphids and pictures of Euceraphis betulae and Uroleucon cichorii that have been presented during a talk at Rennes (France); Geoffrey A. Parker for discussing his old and classic publications on yellow dung flies with me via e-mail; Sebastian Domhof for precious statistical advice as well as Lars Reimer for helpful chats on statistics; Angelika Metje for tending thistles; Fabien Halkett for a tip at Rennes; Theresa Jones and Ndowa Lale for some editing; Pierre Capy, Tony Dixon, Thomas Hoffmeister, Dinah Hales, Bart Kempenaers, Kate Lessells, Stefan Vidal, Donald Waller, Ron Woodruff, and various anonymous reviewers for helpful comments on earlier versions of submitted papers. 


\section{Contents}

Acknowledgements

Preface

Introduction 1

$\begin{array}{ll}\text { Materials } & 2\end{array}$

Field studies $\quad 2$

Laboratory studies $\quad 3$

Results 4

1. Copula duration and sperm economy in Uroleucon cirsii 4

Appendices 9

1.1 Increasing egg number of virgin sexual females in U. cirsii 9

1.2 Life times in a cohort of virgin sexual females of U. cirsii 10

$\begin{array}{ll}1.3 \text { Aphid sperm comes in bundles of co-operating sperm cells } & 11\end{array}$

2. Marginal value theorem and mate competition in Schizolachnus obscurus $\quad 14$

Appendix: 2.1 The model of G.A. Parker and R.A. Stuart 19

3. Sex ratios mate guarding in aphids $\quad 21$

Appendix: 3.1 Patterns of mating behaviour other than guarding 25

4. Kin competition and differential sex ratios in aphids $\quad 27$

Appendix: 4.1 First instar weights of sexual females and males in U. cirsii 34

5. Population density sex allocation in U. cirsii 36

6. Jumping genes, ancient asexual scandals, and the paradox of sex 41

$\begin{array}{ll}\text { General Conclusions } & 47\end{array}$

Interactors, replicators, and evolutionary theory $\quad 47$

Interactor selection: Which strategy survives? 48

Replicator selection: Who benefits? 50

$\begin{array}{ll}\text { Summary } & 51\end{array}$

Zusammenfassung $\quad 53$

References $\quad 55$

$\begin{array}{ll}\text { Curriculum vitae } & 63\end{array}$ 


\section{Preface}

\section{Why sex? A parody on the paradox*}

After decades of establishing concepts such as fitness, adaptation, and reproductive success on top of one another, a paradox quaked evolutionary theory in the early seventies (see Williams 1975, preface). Why should sex have evolved in the first place? Nature did not obey theory any more! Asexually reproducing organisms pass on $100 \%$ of their genetic information to their offspring, while sexually reproducing organisms inherit only $50 \%$. This is the twofold advantage for asexual reproduction, and other obvious "costs" of sexual reproduction are apparent although harder to quantify. To find a sexual partner, mate, and reproduce successfully costs time and energy. And so does the often necessary courtship, when the genders need to overcome conflicting interests. So, while there should not have been a lot of sex in theory, it obviously was the dominant way of life among animals and plants. George C. Williams (1975, p. V) opened his seminal book on Sex and Evolution with the proclamation of the crisis: "This book is written in the conviction that the prevalence of sexual reproduction in higher plants and animals is inconsistent with current evolutionary theory. [...] Many well informed readers may disagree with much of my reasoning, but I hope at least to convince them that there is a kind of crisis at hand in evolutionary biology".

Much research and modelling has been done since to answer the question: Why is there sex? But instead of getting one straight answer more and more questions cropped up. Two different kinds of questions can be discriminated: 1) How much of a genome is reproduced and what advantage does this convey? 2) In which way is reproduction achieved and what advantage does this convey? Comparing reproductive units, like genes or organisms, while answering the first question leads to the paradox: 100\% inheritance (asexual reproduction) will be of two-fold advantage compared to $50 \%$ (sexual reproduction), although sexuality is the prevalent mode of reproduction among animals and plants.

The answers to the second question are manifold and complex often involving models. As a general result, sexual reproduction has advantages under circumstances like intense sibling competition; an onslaught of diseases combined with vulnerability to parasites and other enemies; accumulation of detrimental mutations; or a saturated and heterogeneous

\footnotetext{
* Dagg, J.L. (2000) Oikos 89: 188-190
} 
environment (Stearns 1987). Asking in which way and under which circumstances reproduction is achieved, these models now have famous nick names like Tangled Bank hypothesis, Red Queen hypothesis, or Muller's Ratchet. But while sexual reproduction will be favoured under these circumstances, nobody was able to cast this into a simple, quantitative advantage exceeding a two-fold ratio. And, like a jack-in-the-box, the original question jumped up again with ever new twists, whenever the paradox seemed to be put to rest: Why should sexual reproduction exist? How can its short term disadvantage be overcome by its long term advantage? Why do ancient asexual species, such as bdelloid rotifers and darwinulid ostracods persist, if asexuality was an evolutionary dead-end in the long run? If the benefits of sexuality could be obtained through facultative or temporary sex, why are most animal species obligatory and continually sexual? Why are asexual organelles within sexual cells, such as mitochondria and chloroplasts, not suffering from piling up mutation loads, parasitic DNA or intra clonal competition? Or why are they not taking over the sexual cells?

\section{Inverting the perspective}

Assuming that nature is not paradoxical in itself, and if instead of asking which advantage sexual reproduction confers to any reproductive unit, we ask the question: What maintains itself through sexual reproduction?, the logical answer is most surprising: It is not any reproductive unit (e.g., gene, organism, group), but the strategy of sexual reproduction itself!

Models are, nevertheless, regularly introduced with reference to reproductive units. For example: "In the production of widely dispersed propagules let genotype $a$ produce them asexually, so that all have the parental genotype $a$. Genotype $b$ produces them sexually, so that they have genotypes $c, d$, e, etc." (Williams 1975, p. 16). "Suppose that in a sexual species, with equal numbers of males and females, a mutation occurs causing females to produce only parthenogenetic females like themselves" (Maynard Smith 1978, p. 3). "Suppose that a female occupies a territory. She produces both sons and daughters" (Charnov 1982, p. 73).

However, models only compare strategies. In Williams's lottery model (1975, p. 15), for example, the players only differ in their strategy of buying tickets. Modelling the logic of animal conflict, Maynard Smith \& Price (1973) stated: "The contestants were programmed as having identical fighting prowess, so that they differed only in the strategies they followed." The same is true for models testing sexual versus asexual reproduction. Thus, only particular reproductive strategies were tested under particular circumstances. 


\section{Reproductive units and strategies racing on arms}

Question one (How much?) can only be answered by stating the (at least) two-fold advantage for asexual reproduction. Hence, all the answers delivering an advantage for sexual reproduction are necessarily answers to question two (In which way?) and cannot properly address question one. The result of a cross-comparison between reproductive units and reproductive strategies is surprising, because ever since Maynard Smith \& Price (1973) introduced the concept of Evolutionary Stable Strategies (ESS) nearly everybody pondering about the riddle of sex got it right somehow, but put it wrong somehow else.

The strategy of sexual reproduction will have the higher reproductive success, if more sexually reproducing units survive and reproduce than would in the case of asexual reproduction. The genetic constitution of the reproduced units is largely irrelevant. The reproductive units, however, would have the higher success if they were to inherit more of their genetic information, no matter how. The genetic constitution of the offspring matters. The evolutionary interests of reproductive unit and strategy are not identical.

Suppose the circumstances are such that the strategy of sexual reproduction will have a higher reproductive success than the strategy of asexual reproduction. Under these circumstances the strategy of sexual reproduction should be expected to "win" against the reproductive units as well! As pointed out above, these units could at least double their reproductive success through asexual as compared to sexual reproduction. In other words, the reproductive unit would lose half its maximum possible reproductive success through reproducing sexually. The strategy of sexual reproduction, however, would lose all: If an individual became asexual the strategy of sexual reproduction would end its existence on this level and within this individual.

According to the logic of arms races, the reproductive unit should be expected to lose this competition. To borrow a notorious example, in the arms race between the cuckoo and its foster-parents the latter can never win. This is so because there are many other aspects of the foster-parents' all day life beneath cuckoos endangering their reproductive success. In order to out-gamble the cuckoo they would have to invest far more of their resources than optimal, and probably fall prey to some other enemy. The cuckoos reproductive success, however, is entirely at stake. It must invest enough to out gamble the foster parents or die out.

The same is true for the strategy of sexual reproduction gambling against the individual reproductive units. The strategy plays an all or nothing game, win or end your existence, while each reproductive unit only plays for half its maximum reproductive success. Therefore, individual reproductive units should not be expected to win this competition! The 
strategy of sexual reproduction should be beaten only, if circumstances change and favour the strategy of asexual reproduction instead.

\section{A just-so story for sex}

If any speculation about the origin of sexuality was needed, one might imagine primordial cells: An event leading to the diploidy of a cell could have been a spontaneous fusion of neighbouring cells, as can still be induced in primordial pond experiments through electromagnetic waves (Küppers \& Zimmermann 1983; Zimmermann \& Küppers 1983). This fusion must not be associated with a reproductive disadvantage. As with a normal cell division, the double amount of genetic information and cell material was transferred into the next generation, it just so happened to end up within one cell. A reproductive disadvantage would lie in biparental reproduction (50\% inheritance) or the polar bodies of gametogenesis, not in cell fusion per se. At the same time, the fused cells could have an advantage over separated cells as explained below.

Margulis \& Sagan (1986) favoured cannibalism among protists as a candidate origin of cell fusion. Nevertheless, they pointed out that desiccation is a common problem for protists (Margulis \& Sagan 1986, p. 149f). In marginal puddles of the primordial ocean this would have been a problem as well. At the same time, it seems more reasonable to situate early evolution in such places than in the wide primordial ocean. By virtue of their lower surface/volume ratio, fused cells will be better protected against desiccation. If crossing over occurred in the cell division following the fusion of two (identical) sister cells, the exchanged genetic information would rather have been identical constituting no reproductive disadvantage for DNA-replicators either.

While recombination did not alter the genetic information initially, a new reproductive strategy had emerged through the event: The strategy of sexual reproduction was incipient in cell fusion and recombination. The survival of this new strategy depended on the ability to preserve itself against the interests of the reproductive units. Initially, however, "it was not worth" preventing cell fusion and recombination from happening. When recombination started to alter the genetic information, it might already have acquired an indispensable function for DNA repair (Bernstein 1977, Bernstein et al. 1985).

\section{Punch line}

In conclusion, only the strategy of sexual reproduction itself enjoys the benefits of sex unless I am missing some essential feature of the situation. 


\section{Introduction}

Aphids are of interest with respect to both applied and basic ecology, because they live in close association with their host plants and have intricate life cycles. At first sight, one might think that the association of aphids with their host plants is of interest to applied research and the peculiarities of their life cycles to basic research. This simplistic view, however, can easily be refuted by pointing out the relevance of one basic feature of aphid life cycles to applied research, cyclic parthenogenesis.

Sexual reproduction takes place in autumn and the fertilised eggs overwinter. The females that hatch from these eggs in spring reproduce pathenogenetically as adults. All the following generations also reproduce parthenogenetically until autumn, when a new sexual generation emerges. This alternation of reproductive modes is called cyclic parthenogenesis. The sexually produced eggs are the cold hardy stage that persists through winter. In spring and summer, however, parthenogenetic females do not lay eggs but give birth to larvae. Moreover, the development of an aphid begins when its mother is still an embryo. Consequently, the embryos inside an adult parthenogenetic aphid carry embryos themselves. This so-called telescoping of generations is a major reason for the high intrinsic rate of increase in aphid populations and the agricultural harm that they can cause. In addition to the differentiation into parthenogenetic and sexual morphs, that into winged and wingless forms is important to aphid ecology, because it allows the colonisation and exploitation of new resources. Hence, the whole life cycle of aphids including the sexual generation is relevant to applied research.

Nevertheless, the ecology of the sexual generation is, except for a few lines of research such as that into the sex pheromone of females (e.g., Pickett et al. 1992), less thoroughly studied than that of the parthenogenetic morphs. Before considering the way in which knowledge concerning the sexual generation of aphids can be applied, however, that knowledge needs to be produced, i.e., basic research is necessary. This dissertation aims at increasing the knowledge of the sexual generation of aphids.

The term strategy has been introduced into biology with the application of game theory to problems of evolutionary biology in this context (Maynard Smith \& Price 1973). Any adaptation can be taken as an evolutionary strategy (Maynard Smith 1982). 


\section{Materials}

\section{Field studies}

Two different field studies were performed on the northern campus of the University of Göttingen during autumn 2000 and 2001. In the first survey, the sex ratio and copula duration of two aphids species were compared. Previous observations revealed that male Euceraphis betulae Koch guard their females after copulation. Male Uroleucon cichorii (Koch), on the other hand, leave their females after copula without guarding. In the second survey, the sex ratio was recorded for Schizolachnus obscurus Börner living on black pines, Pinus nigra Arnold, and the mating behaviour of male was compared between colonies with one male and colonies with more than one male. Schizolachnus pineti (Fabricius) would have been just as easy to observe, but its host plant, Pinus sylvestris L., tends to grow 'lammas' shoots under favourable conditions. These shoots grow during August, when the switch to sexual reproduction is triggered in the individuals that will become the grandmothers of the sexual generation (telescoping of generations). It has been shown that the asexual side-lineages or paracycles of $S$. pineti emerge from such late growing shoots (Dagg 1999). No paracycles are known for S. obscurus and the surveyed black pines obviously grew no late shoots in 2001 . The sex ratios should, therefore, not be confounded by parthenogenetic females being mistaken for sexual females. Nevertheless, I have observed a few regenerative shoots in the following season, in August 2002, where young twigs have been cut or broken.

Both field studies were characterised by small populations of host plants. In autumn 2000, the hawksbeard, Crepis tectorum L., that hosted U. cichorii was scattered over a weed fallow area of an estimated $300-500 \mathrm{~m}^{2}$. E. betulae was found on three birch trees, Betula pendula Roth, of an estimated height of 7-9 meters. Interestingly, no E. betulae could be found on the same trees in the following season, but a tiny curculionid beetle sat on every other leaf. In autumn 2001, two black pines of an estimated height of 8-10 meters served for studying S. obscurus. In order to avoid pseudo-replication, an attempt was made at sampling the entire population, i.e., the aphids on all accessible twigs or all plants of hawksbeard in the weed fallow were treated as cohorts. More specific details of the materials and methods can be found in the corresponding chapters 2 and 3 of the results section. 


\section{Laboratory studies}

Two different facilities were used for the laboratory studies. The experiments on copula duration and mate choice in $U$. cirsii were performed under the supervision of Prof. A.F.G. Dixon at the University of East Anglia in Norwich, UK, 1999. Seeds of the creeping thistle, Cirsium arvense (L.) Scop., were collected from plants on the campus of the University of East Anglia and a greenhouse culture of host plants was established. A continual culture of $U$. cirsii was also established from aphids collected at the campus and held under long-day conditions in a separate greenhouse. Sexual reproduction was established through short-day conditions within climatic cabinets. Further details can be found in chapter 1 of the results section. The laboratory experiments on sex allocation were performed under the supervision of Prof. S. Vidal at the University of Göttingen, Germany, 2000, 2001. The cultures were established afresh from field collections of seeds and aphids on the northern campus of the University of Göttingen.

$U$. cirsii has been favoured for laboratory studies for several reasons. First of all, it is one of the largest aphid species (up to $6 \mathrm{~mm}$ length) and, therefore, mating behaviour can easily be observed. Secondly, asexual or intermediary clones are not known in U. cirsii. The annual life cycle of the host plant and the specialist commitment of $U$. cirsii to thistles do not, in any case, allow asexual overwintering. Finally, the males are born leaf green in colour, whereas all females are chocolate brown (fig. 0.1). This feature is extremely convenient. The sexes can be identified as first instar nymphs and readily separated for later experiments on mating behaviour. It also allows an easy and exact determination of the primary sex ratio.

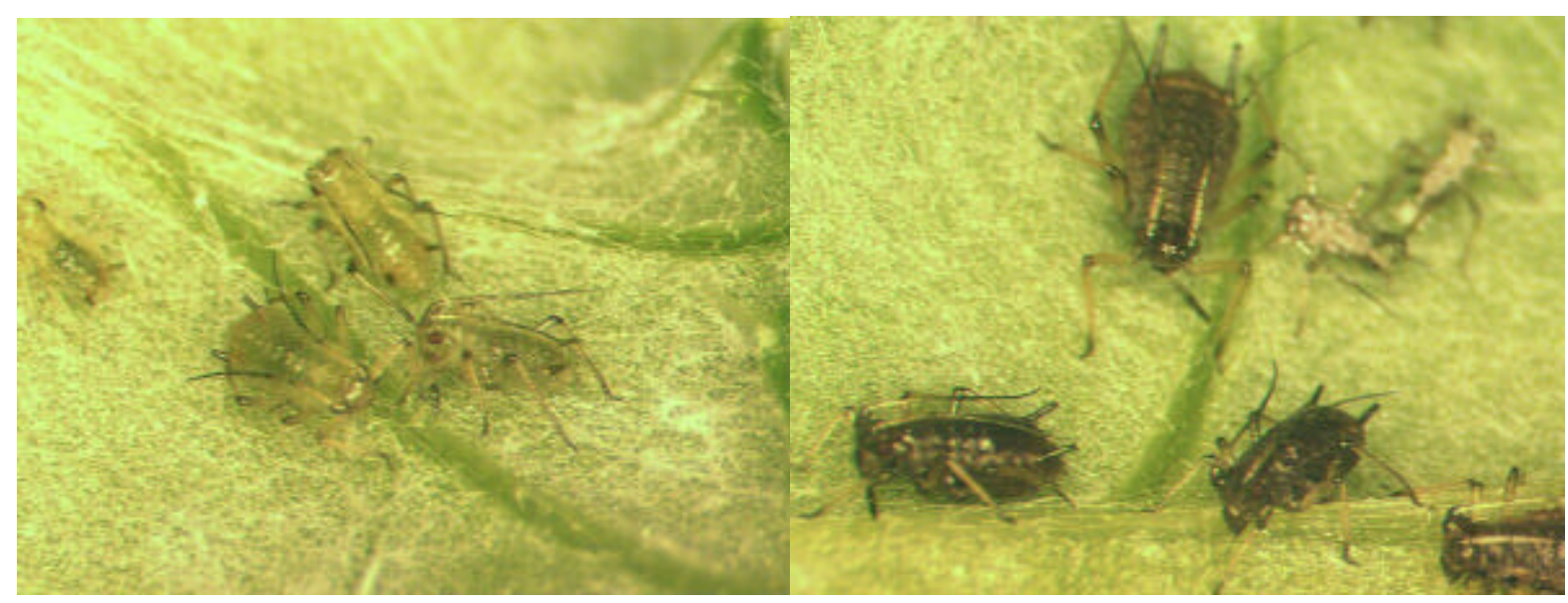

Fig. 0.1: Male $1^{\text {st }}-2^{\text {nd }}$ and female $2^{\text {nd }}-3^{\text {rd }}$ instar nymphs of $U$. cirsii. Adults would have a long upwards pointing cauda (not a short backwards pointing one) with a colour resembling that of the tibiae. 


\section{Results}

\section{Copula duration and sperm economy*}

Optimal mating theory has been pioneered by Geoffrey Parker and colleagues (e.g., Parker, 1970a; Parker \& Stuart, 1976) who studied the yellow dung fly, Scatophaga stercoraria (L.). In this system, 'sperm economy' (i.e., the production, storage, and use of sperm) can be modelled as follows: 1) sperm is not a limiting factor for males, they can always invest more if necessary; 2) newly transferred sperm instantly mixes with the contents of the female's storage organ; 3) each amount of newly transferred sperm displaces an equal amount of fluid or stored sperm from the female's storage organ; 4) the sperm of the last male to mate gains precedence in fertilising the eggs of the next batch (e.g., Parker et al., 1990; Parker \& Simmons, 1991; Simmons et al., 1999). Thus the sperm store can be treated like an urn with different marbles inside, and the risk of sperm displacement rising with the portion of a male's sperm in the store. This model predicts a copula duration which ensures that the last male to mate with a female will fertilise about $80 \%$ of the eggs laid in the next batch as found in experiments (Parker, 1970a; Parker \& Stuart, 1976; Birkhead \& Parker, 1997). As a consequence of sperm displacement and optimisation of paternity at $80 \%$, a male will copulate as long, on average, with a virgin female as with one that has just been mated.

Later research on yellow dung flies has also found differential effects of characters like body size have been studied. Males that are larger than average will copulate for a shorter time, because they can gain more females through take-overs and their rate of sperm transfer and thus sperm displacement is higher than for smaller males (e.g., Parker \& Simmons, 1994; Charnov \& Parker, 1995; Birkhead \& Parker, 1997). The size of the female has also been found to be important (e.g., Charnov \& Parker, 1995; Parker et al., 1999).

Without size differences, however, the duration of subsequent copulas remains constant. Constant average copula duration can be taken as indirect evidence for the nature of sperm economy in S. stercoraria. If, in another species, subsequent copulas became longer or shorter, the production, storage, and use of sperm should somehow differ from that in $S$. stercoraria. This has been tested for an aphid species.

\footnotetext{
* in press, European Journal of Entomology
} 


\section{Methods}

Uroleucon cirsii (L.) is a large aphid species $(4-5.2 \mathrm{~mm})$ that lives on the leaves and stems of some thistle species, e.g., Cirsium oleraceum (L.) or C. arvense (L.), but does not alternate between hosts. That is, it occurs on a range of species throughout the year, but does not have special summer and winter hosts. Parthenogenetically over-wintering lineages are not known for this species. Seeds of $C$. arvense and parthenogenetic females of $U$. cirsii were collected in 1999 on the campus of the University of East Anglia in Norwich, and a greenhouse culture was established and held under long day conditions (18h light, $20^{\circ} \mathrm{C}$ ). While the animals for this culture came from one field colony, the possibility that they stemmed from more than one clone cannot be entirely excluded. Parthenogenetic females from this culture were transferred to short-day conditions (12h light, $15 \mathrm{C}^{\circ}$ ). The sexual animals of this species can be easily discriminated, because the males are born leaf green and the females chocolate brown (fig. 0.1). The sexual females and males were separated as new-born nymphs and transferred to plants under cylindrical cages (30 cm high with gauze sealed wholes for ventilation) into separated but identical climatic cabinets. Thus, animals chosen for experimentation had not previously mated.

Mating was observed on leaves, the petioles of which were inserted into watered blocks of floral foam inside plastic boxes $(7.5 \times 4.5 \times 2 \mathrm{~cm})$, which had a hole covered with gauze for ventilation. Mating behaviour was observed through the front window of a climatic cabinet at $15^{\circ} \mathrm{C}$ and a light intensity of $93 \mu \mathrm{E} \cdot \mathrm{m}^{-2} \cdot \mathrm{s}^{-1}$ at the level of the plastic boxes. Copula duration was measured with a hand-held stop watch. All observations were made between 90 and 210 minutes after the lights came on. Virgin males and females were chosen andom for the following experimental groups.

\section{Group 1: One male with different females}

One male was placed together with 5 females. Males that did not mate within half an hour were discarded and further observation was broken off if no second mating occurred within half an hour after the first one. The duration of the first and second copulation of a male with females were recorded. Events of double mating with the same female were excluded from the analysis. This was repeated until 46 instances of one male mating with two different females had been observed. 


\section{Group 2: One female with different males}

A female was placed in a box containing 5 males. Females that were not mated within half an hour of the start of the observation was discarded and further observation was broken off if no second mating occurred within half an hour after the first one. The time spent in copulation by the first and second male was recorded. Events of double mating with the same male were excluded from the analysis. This was repeated until 48 instances of one female mating with two different males had been observed.

\section{Group 3: Single pairs allowed to copulate twice}

A male and a female were placed in a standard box. Pairs that were reluctant to mate were discarded and further observation was broken off if no second mating occurred within half an hour after the first one. The duration of two copulas was recorded. This was repeated until 34 instances of one male mating with twice with the same female had been observed.

\section{Statistical analysis}

The differences in copula duration (1st -2 nd) were tested against one another. The KruskalWallis-test followed by pair-wise comparisons of the Mann-Whitney-Wilcoxon U-statistic was chosen as the non-parametric alternative to an ANOVA. A normal distribution with a mean of zero and a standard deviation equal to the highest one among the experimental groups $(\mathrm{SD}=2.33$ ) served as a control population, from which a random sample of a size equal to the smallest one among the experimental groups $(\mathrm{N}=34$ values) was drawn as the control sample. This control sample happened to have a mean of 0.11 and a standard deviation of 2.18. It represents a result from a population with equal duration of first and second copula.

Missing values arose from instances where no second mating occurred within half an hour after the end of the first mating. The events of a second copula or no second copula respectively can be taken as two distinct outcomes of the experiments. These categorical data were compared with Fisher's exact test for each pair of experimental groups (1-2, 2-3, 3-1).

\section{Results}

The duration of the second copula was consistently shorter than the duration of the first copula in all experimental groups (fig. 1.1). The Kruskal-Wallis statistic had a small probability $(\mathrm{H}=25.58, \mathrm{p}<0.001,3 \mathrm{df})$. The results of the pair-wise comparisons are summarised in table 1.1. Copula duration reduced significantly between the first and second 
mating in all three groups. With one male mating twice, this reduction was significantly weaker than with one female mating twice. Pairs mating twice showed the strongest reduction, but this did not differ significantly from one female mating with different males.

Table 1.1: Non-parametric pair-wise comparisons

\begin{tabular}{lcccc}
\hline comparison & U-statistic & p-values & $\alpha$ & $\mathrm{K}$ \\
\hline control-group1 & 543 & $0.020^{*}$ & 0.0253 & 2 \\
control-group2 & 405 & $<0.001^{*}$ & 0.0085 & 6 \\
control-group3 & 253 & $<0.001^{*}$ & 0.0102 & 5 \\
group1-group2 & 720.5 & $0.004^{*}$ & 0.0127 & 4 \\
group1-group3 & 1065.5 & $0.006^{*}$ & 0.0169 & 3 \\
group2-group3 & 871.5 & 0.601 & 0.0500 & 1 \\
\hline P-values & & 0.0100
\end{tabular}

P-values with asterisk are significant at the $\alpha$ levels associated to $\alpha=0.05$ as calculated by the Dunn-Sidák method (cf. Sokal \& Rohlf 1995, p. 239): $\alpha^{\prime}=1-(1-\alpha)^{1 / K}$, where $\mathrm{K}$ is the rank of the p-value.

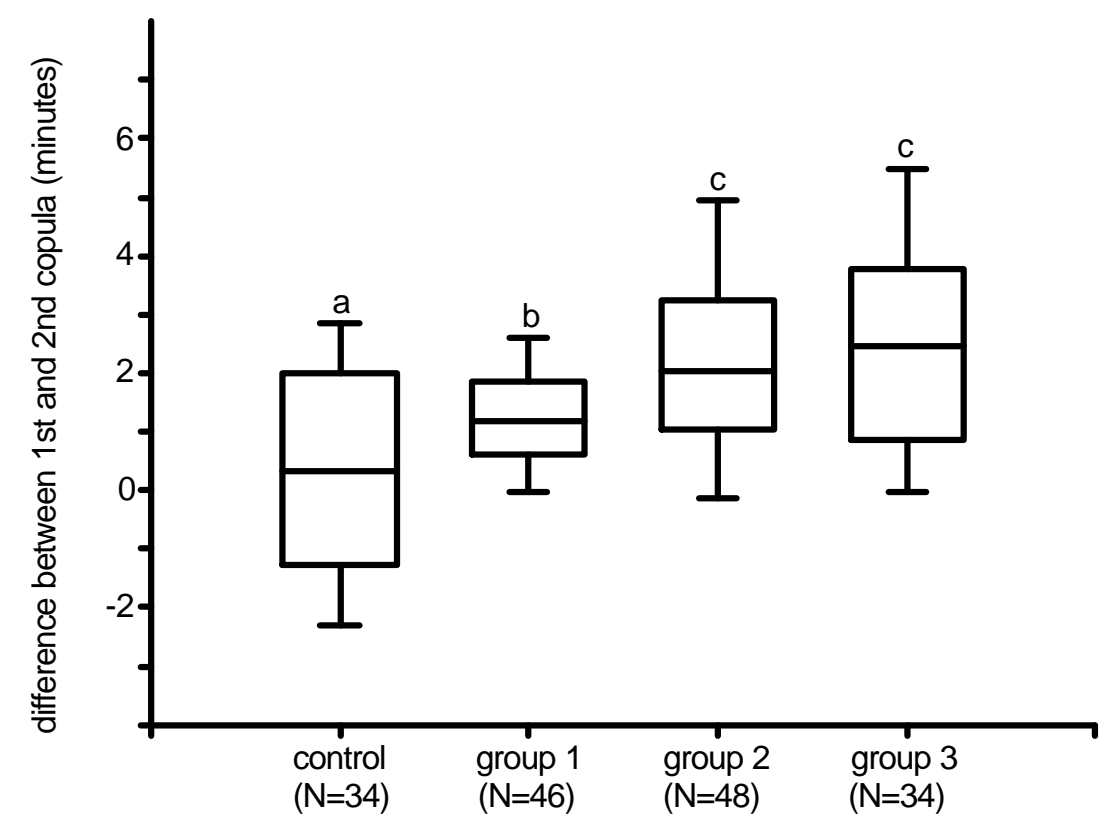

Fig. 1.1: Box-and-whiskers plots for the difference in duration between the first and second copula. Boxes cover 50 percent of the variance from the 25th to the 75 th percentile and are divided at the median. The whiskers stretch to the 10th and 90th percentile respectively. The control was sampled from a normal distribution with a mean of zero and a standard deviation of 2.33 (median $=0.32$ ). Group 1: one male had access to five females (median $=1.18 \mathrm{~min})$. Group 2: five males had access to one female (median $=2.02 \mathrm{~min})$. Group 3: one male had access to one female $($ median $=2.45 \mathrm{~min}$ ). Different letters mark significantly different samples. 
Second copula events were significantly more common, when one male had access to different females in group 1 than vice versa in group 2 (Pearson's Chi-square $=6.091 ; 1 \mathrm{df}$; Fisher's exact test: $\mathrm{p}=0.019)$. Again, second copulas were more common in group 2 (1female : 5males) than in group 3 (Pearson's Chi-square $=8.221 ; 1 \mathrm{df}$; Fisher's exact test: $\mathrm{p}$ $=0.005)$. The last comparison between group 3 and group 1 must, of course, be still more significant (Pearson's Chi-square $=24.111 ; 1 \mathrm{df}$; Fisher's exact test: $\mathrm{p}<0.001$ ).

\section{Discussion}

According to Eberhard (1998), the apparently arbitrary and strange antics of many courtship behaviours (e.g., males of different insect species lick, tap, rub, kick, stroke, shake, squeeze, feed, sing to, and vibrate the female during copulation) are signals for the females (e.g., for discriminating con-specific males from foreign males, attending ants, or parasitoids) and evolved under cryptic female choice for reliable signalling. Like Myzus persicae (Sulzer) (see Doherty \& Hales, 2002) and many other aphid species $U$. cirsii shows no striking courtship behaviour, but Schizaphis borealis Tambs-Lyche or Cinara cuneomaculata (Del Guercio) do (Pettersson, 1968; Dagg \& Scheurer, 1998). While it would be interesting to know why some aphid species perform striking courtship behaviours but others do not, parameters like copula duration can yield indirect evidence on issues like sperm economy. Other behavioural parameters like search time should also be interesting in this respect (e.g., Kozlowski, 1991).

The present results suggest that the sperm production, storage, and use of $U$. cirsii differs from the one in the yellow dung fly, S. stercoraria. It is therefore necessary to ask which of the four assumptions on sperm 'economy' (unlimited sperm resource of males, instant mixing, sperm displacement, last male precedence) need to be changed in order to explain these results. The reduction of the duration of the copula of individual males (group 1) suggests a limitation in the amount of sperm a male has at its disposal (Wedell et al., 2002, p. 315) or a 'Coolidge effect' (Wedell et al., 2002, p. 318). This is a progressive decline in a male's investment in a female over successive mating events combined with a renewed sexual interest in a novel females that promotes sperm economy. The reduction in the duration of the copula of individual females (group 2) could be expected, if males were not able to displace stored sperm. Reduced copula duration might therefore be a simple consequence of a limit on the female's capacity to store sperm. Forgoing second copulation as found in the categorical analysis might simply be an extreme of reduced copula duration. 


\section{Appendices}

\subsection{Increasing egg number of virgin sexual females in $U$. cirsii}

Sexual females that have been reared in standard boxes were transferred onto potted plants after their imaginal moult. Thus females of the same adult age lived on the same potted plants inside a climatic cabinet with no males. Females of known age were taken and dissected. Only mature eggs that did not disintegrate during dissection or on being touched with the hairs of a fine paint brush were counted. Egg number is plotted against adult age in figure 1.2.

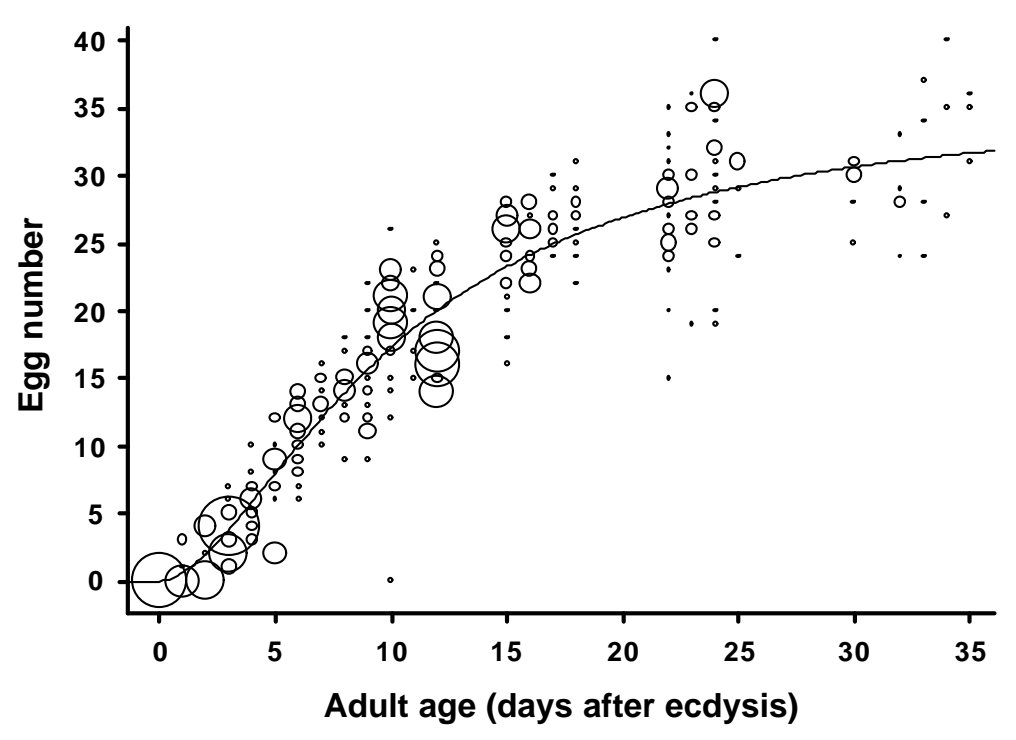

Fig. 1.2: Bubble size indicates the number of virgin females with a certain combination of age and egg load.

Females of the same plants were brought together with males. A curious mating behaviour did sometimes occur with virgin females older than three weeks. Where normally, several minutes of motionless copulation commenced, the males repeatedly jerked their genital plates free from the ones of the female only seconds after having fused them. After several unsuccessful trials, the males abandoned these females. Inspection of these females under a binocular revealed that the genital opening was blocked by thickened and sticky honeydew.

The eggs of unfertilised females might swell the abdomen up to an unbecoming size, when air can reach the honeydew in the hind gut and dry it. This observation could explain the finding of Doherty \& Hales (2002) that fertilisation success sank with the age of the female. They did not closely observe the mating behaviour or examine the genital opening, but report on the number of fertile eggs laid by sexual females of Myzus persicae (Sulzer) that had been brought together with males at varying ages. 


\subsection{Life times in a cohort of virgin sexual females of Uroleucon cirsii}

One cohort of virgin sexual females of the same age on a potted thistle in a good condition was monitored for the life time of the females. Although this experiment would have to be replicated, in order to allow a statistically hedged statement, the result is consistent with other observations.

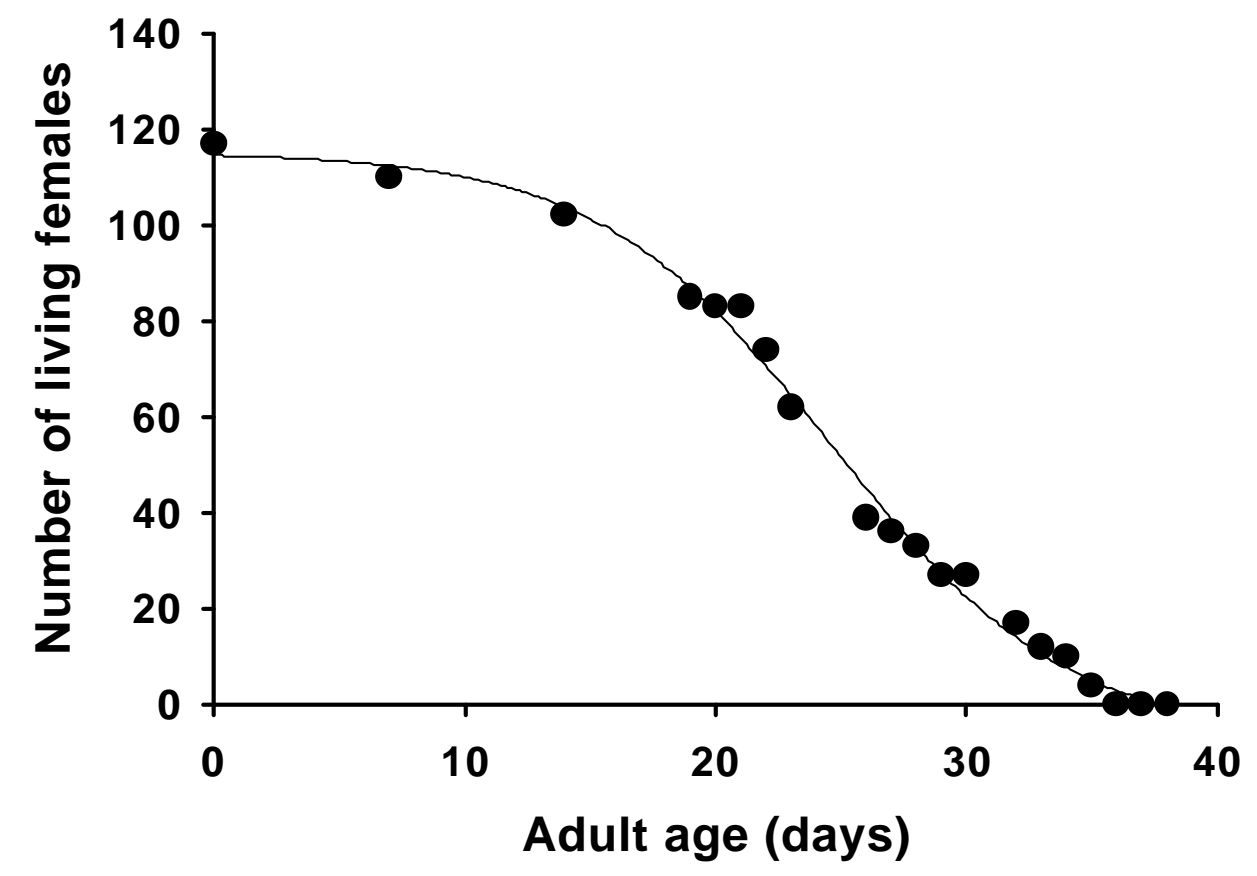

Fig. 1.3: Number of survivors of a cohort of virgin sexual females on a host plant that grew from ca 20 to $60 \mathrm{~cm}$ height proved to be suitable for the reproduction of a parthenogenetic female even from day 22 onwards.

The number of survivors started to decline markedly after three weeks (fig. 1.3). This was also the adult age after which the first females occurred that had been blocked by thickened honeydew (see above). Some females lingered on for more than 35 days, but females that are older than 30 days can probably no longer be fertilised properly. 


\subsection{Aphid sperm comes in bundles of co-operating sperm cells}

While sperm cells fend for themselves in humans and many other animals, social evolution can result in sperm co-operation under certain circumstances (Trivers, 1985). If closely related sperm cells from one male have to compete with those from other males, co-operation among related sperm should be advantageous. Spermatogenesis is relevant to the likelihood of sperm co-operation in aphids. While all female aphids including parthenogenetic ones carry two X chromosomes (XX), males have only one (X0). Nevertheless all fertilised eggs become female, because all viable sperm cells retain the male's $\mathrm{X}$ chromosome during meiosis (Blackman, 1987), which constitutes a large part of the aphid genome (e.g., Spence \& Blackman, 1998). The relatedness of the sperm cells from one male must be considerably higher than $50 \%$, simply because they all share an identical $\mathrm{X}$ chromosome. Therefore, a genetic base for kin selection towards sperm co-operation is present in aphids.

In order to explore the mode of sperm transfer and storage in aphids, fertilised females were killed in Ringer solution for Grasshopper sperm cells (cf. Buck, 1953, p. 161), at various times after copulation. Mating took place at $15^{\circ} \mathrm{C}$ and dissection at room temperature. The sperm stores (fig. 1.4) were prepared on microscope slides and examined under a microscope.

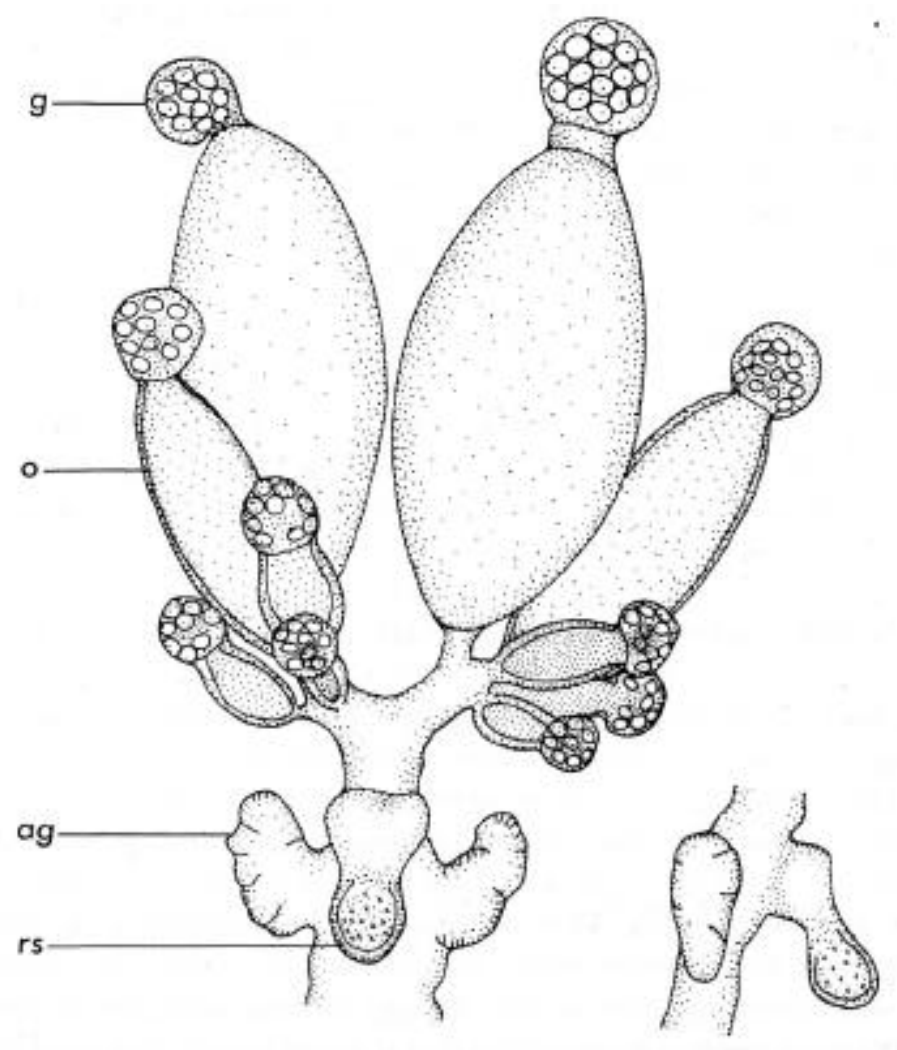

Fig. 1.4: Reproductive system of an adult sexual female before oviposition in dorsal view, with lower part shown on right in lateral view; g: germarium; o: oocyte; ag: accessory gland; rs: receptaculum seminis. The drawing by A.J. Polaszek is reprinted from Blackman (1987, p. 165) with kind permission by R.L. Blackman. 
The following observations should be helpful for future research on sperm economy in aphids. Sperm comes in flexible bundles with the sperm heads sticking together and the flagella moving synchronously. Sperm bundles become spherical inside the receptaculum seminis, but are lengthy when squeezing through the genital tract. In a female that had copulated until minute 20 after copula start and was killed at minute 30 , the sperm bundle had not yet invaded the female's receptaculum seminis. As preparation took about ten minutes, the time from insemination to observation can be estimated at 20 to 40 minutes. In another female that had copulated until minute 5.5 and was killed at minute 60 , the sperm just invaded the receptaculum as a lengthy rather than spherical bundle. Adding preparation duration, the time for the sperm to move inside the genital tract can be estimated at 64.5 to 70 minutes. The status of sperm in a female that had copulated until minute 6.8 and was killed at minute 120 was not clear. Finally, in a female that was killed at minute 180 (after having copulated for 5.5 minutes) the receptaculum seminis was empty but contracting rhythmically. When taken for dissection, this female was already in oviposition posture and dissection revealed that the first egg was already about to be laid (sat just in front to the anus). This suggests that the sperm bundle had just emigrated from the receptaculum. The time from insemination to observation can be estimated at 184.5 to 190 minutes in this case.

The duration of sperm storage should take longer in younger females that do not yet have any eggs mature enough for oviposition. The same should be true, if the dissection and preparation had been undertaken at $15^{\circ} \mathrm{C}$ rather than room temperature. Nevertheless, the best time for studying sperm storage might be between one and three hours after copulation. Figure 1.5 shows a sperm clump that has been squeezed out of its receptaculum by exerting pressure on the cover slip. The flagella stopped beating on being squeezed out of the receptaculum indicating that the Ringer solution has not been ideal for sperm survival.

Hayashi (1996, fig. 5; 1998, fig. 1) found bullet and rod shaped sperm bundles from spermatophores of male fishfly (Megaloptera: Corydalidae) that are externally attached to the genitals of the females. The velocity of these sperm 'projectiles' depends positively on the bundle's size and negatively on the viscosity of the medium (Hayashi, 1998) suggesting sperm co-operation as an adaptation to long distance movement in a viscous medium.

Hamilton's rule states the ultimate condition under which altruism can evolve:

$$
r b-c>0,
$$

where $b$ is the reproductive advantage gained by the beneficiary, $c$ the cost paid by the benefactor and $r$ their relatedness. Both ultimate (Trivers, 1985) and proximate (Hayashi, 1998) conditions could select for sperm co-operation in aphids. If genes that lead to the 
agglutination of sperm heads, for example, were situated on the $\mathrm{X}$ chromosome, the relatedness between the benefiting and the benevolent replicator would be maximal $(r=1)$, because all sperm cells get an identical $\mathrm{X}$ chromosome. At the same time, the cost $c$ to sperm cells that will not eventually fertilise an egg should be minimal, because all sperm cells can move quicker and at a lower risk of being absorbed in mucus or eaten by phagocytes when participating in a sperm bundle (Hayashhi, 1998). Hence all sperm cells will increase their chance to fertilise an egg by co-operating as compared to the chance of individual sperm cells.

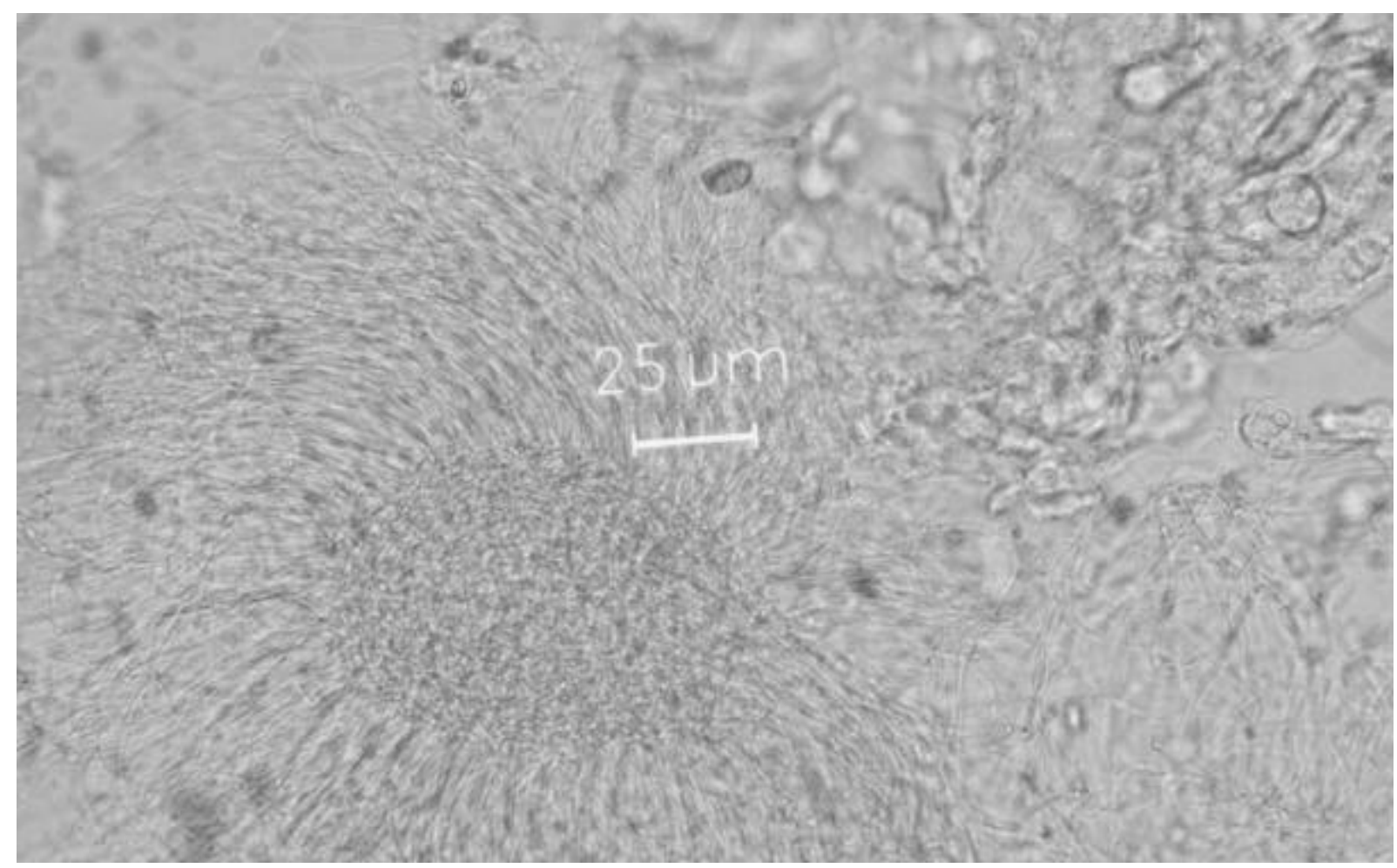

Fig. 1.5: A bundle of sperm heads of $U$. cirsii to the left and below the scale. The long flagella extend outward from the bundle. The top right part of the picture is full of pieces of the broken receptaculum seminis. Individual sperm heads can be seen as small light dots below these fragments and to the right of the sperm bundle.

Given that aphid sperm comes in co-operating bundles, both instant mixing and continuous sperm displacement seem to be rather unlikely assumptions. Thus three simplifications that are commonly assumed - unlimited sperm in males, instant mixing, and sperm displacement - do not seem to apply to aphids. Nevertheless, last male precedence is not cogently related to these features (Simmons \& Siva-Jothy, 1998). It is still possible, for example, that the last sperm bundle to invade the sperm store remains closer to the exit and thus to the eggs. Further studies are needed to find out how competition between sperm bundles takes place in aphids. 


\section{Marginal value theorem and mate competition*}

The marginal value theorem predicts that the average time spent in a patch (Charnov 1976) or with a female (Parker \& Stuart 1976) should increase along with the average time needed to search for patches or females. One factor that increases search time is the competition for mates from other males.

The mating behaviour of the pine needle aphid Schizolachnus obscurus Börner is easy to observe in the field. It is does not alternate between summer and winter hosts and is common on the needles of the black pine, Pinus nigra Arnold, where it forms linear colonies on the round (outer) needle surface with animals sitting like beads on a string. The sexual generation of this aphid species is characterised by strongly female biased sex ratios. The sexual females are wingless, while the winged males search for them. Sexual females of $S$. obscurus always lay eggs in batches of four, which are laid on the flat (inner) needle surface, again, like beads on a string. The limited space for eggs on one needle might be a dispersing stimulus for egg laying females. Before oviposition, however, the females tend to occur in colonies. Hence a male aphid that has found one female should have a good chance to find another within a short time and at a relatively low risk of competition from other males in comparison to species like the yellow dung fly Scatophaga stercoraria (L.), which has strongly male biased operational sex ratios (e.g., Parker 1970a, b). Here, I test how mate competition influences mating behaviour in a field population of S. obscurus, by applying an approximate solution of the marginal value model by Parker \& Stuart (1976).

The copula duration of male $S$. stercoraria needs to increase exponentially, in order to yield a linear increase in the so called $P 2$ values, i.e., the proportional gain in fertilised eggs (Parker \& Stuart 1976). Nevertheless, a parabola that merges into a constant at its peak is a good approximation as well:

$$
\begin{array}{ll}
G(C)=\frac{G_{\max } C}{C_{p k}{ }^{2}}\left(2 C_{p k}-C\right), & \text { for } C<C_{p k}, \\
G(C)=G_{\max }, & \text { for } C>C_{p k},
\end{array}
$$

where $G$ is the proportion of eggs fertilised, $C$ the copula duration, and $C_{p k}$ the time that corresponds to the peak of the parabola (see appendix, fig. 2.2). This allowed an analytical solution for the dependence of the optimal copula duration $C_{o p t}$ on the search time $S$ :

$$
C_{o p t}=-S+\sqrt{S^{2}+2 S C_{p k}} .
$$

\footnotetext{
* submitted to Ethology
} 
See Parker \& Stuart (1976) for the mathematical derivation. Assuming that the gain function of $S$. obscurus is also exponential, this formula can be used to calculate the shaping factor $C_{p k}$ of the parabolic approximation in the absence of data on P2 values:

$$
C_{p k}=\frac{C^{2}}{2 S}+C
$$

\section{Methods}

The sexual generation of S. obscurus was observed between the $29^{\text {th }}$ Sept. and $14^{\text {th }}$ Nov. 2001 on the northern campus of the University of Göttingen. Black pine needles stand in pairs with a common sheath at the base. All aphids on such a needle pair were considered one colony. I sampled all the accessible twigs of two free standing trees of an estimated height of 8 meters, in order to record the sex ratios of adults. Adults were sexed and the operational sex ratio was determined as the portion of males among adults in colonies with at least one adult male and one adult female.

Behavioural observations were performed on the days following the sex ratio estimations and were compared between colonies with one male and colonies with two males respectively. The ambient temperature was recorded once for each colony observed. These temperature data were tested against the number of males per colony, in order to check for an unplanned bias in the ambient temperature. Likewise, the number of adult females was tested against the number of males per colony.

When an active (i.e., walking or mating) male was found within a colony, it was observed. The observation of a male was continued until he left the colony or stopped being active (i.e., rested for more than 10 minutes). A complete behavioural cycle of a male was defined as a succession of a search (S), copula (C), and post-copula (PC). Incomplete behavioural cycles occurred at the start and the end of an observation as well as in some instances, when a male directly copulated for a second time without searching after postcopula. In order to avoid pseudo-replication, only the last complete behavioural cycle to occur before the end of an observation were used for analysis. This standard was chosen, because observations of males started at any stage of their sexual activity and first or intermediate cycles could not be determined. Males for whom no complete behavioural was observed were excluded from the analysis. Thereafter, the sample size happened to be 15 both for colonies with one male and colonies with two males.

$C_{p k}$ was calculated for these samples by entering the $C$ and $S$ values in the above equation (3) and averaging for colonies with one and two males respectively. The optimal 
copula duration corresponding to a given search time could now be calculated from equation (2). In order to test this model against an independent data set, search and copula times were averaged for data previously excluded form analysis. The optimal values of copula duration predicted for theses search times were compared with the observed ones.

\section{Results}

Table 2.1 shows that the sex ratio of $S$. obscurus is indeed strongly female biased. The ambient temperature varied around $15.3^{\circ} \mathrm{C}(\mathrm{SD}=1.6)$ for colonies with one male and $15.4^{\circ} \mathrm{C}$ $(\mathrm{SD}=1.6)$ for colonies with two males $(\mathrm{U}=63, \mathrm{p}=0.853)$. The average number of females was $3.4(\mathrm{SD}=1.6)$ in colonies with one male and $4.0(\mathrm{SD}=1.4)$ in colonies with two males, which was neither a significant difference $(U=72.5 ; p=0.231)$.

Table 2.1: Sex ratios and related parameters in Schizolachnus obscurus.

\begin{tabular}{lrrrrrr}
\hline $\begin{array}{l}\text { sampling } \\
\text { date }\end{array}$ & $\begin{array}{r}\text { overall } \\
\text { sex ratio }\end{array}$ & $\begin{array}{r}\text { no. needles } \\
\text { colonised }\end{array}$ & $\begin{array}{r}\text { no. colonies } \\
\text { with any male }\end{array}$ & $\begin{array}{r}\text { colonies with } \\
\text { no. males }>1\end{array}$ & $\begin{array}{r}\text { operational } \\
\text { sex ratio \% }\end{array}$ & $\begin{array}{r}\text { no. colonies } \\
\text { operational }\end{array}$ \\
\hline 29.09 .01 & $01 / 134$ & 143 & 1 & 0 & 20 & 1 \\
09.10 .01 & $34 / 291$ & 135 & 26 & 6 & $31(13)$ & 25 \\
18.10 .01 & $51 / 444$ & 197 & 34 & 8 & $29(12)$ & 34 \\
23.10 .01 & $47 / 442$ & 214 & 25 & 7 & $30(12)$ & 25 \\
31.10 .01 & $16 / 352$ & 220 & 11 & 2 & $43(8)$ & 11 \\
13.11 .01 & $02 / 221$ & 166 & 2 & 0 & - & - \\
\hline
\end{tabular}

The overall sex ratio is given as: total no. males/total no. adults. The operational sex ratio is given as the mean portion (standard deviation in parentheses) of males among adults in colonies with both adult males and females. The number of these 'operational' colonies is also given in the last row. The number of needles colonised in excess of the total number of adult individuals at 29.09.01 is due to colonies of nymphs. The 2 males found at 13.11.01 sat alone and with 8 nymphs respectively.

Figure 2.1 gives the box-and-whiskers plots for the absolute values of the searches (S), copulas (C), and the post-copulas (PC) in colonies with 1 and 2 males respectively. The median search time increased from $2.20 \mathrm{~min}$ in colonies with one male to $3.38 \mathrm{~min}$ in colonies with two males, while the median copula duration remained fairly constant with $3.48 \mathrm{~min}$ in colonies with one male and $3.33 \mathrm{~min}$ in colonies with two males. The median post-copula duration roughly doubled form $0.33 \mathrm{~min}$ in colonies with one male to $0.70 \mathrm{~min}$ in colonies with two males. This doubling was due to an increased frequency of prolonged post-copula associations. Thus, the frequency of post-copulas lasting for longer than 1 min was $3 / 15$ in colonies with one male, but $6 / 15$ in colonies with two males. Likewise, the frequency of post- 
copulas lasting for longer than 2 min was $0 / 15$ in colonies with one male but $4 / 15$ in colonies with two males; and the frequency of post-copulas lasting for longer than 4min was $0 / 15$ and $2 / 15$ respectively. If it was not jeopardised for pseudo-replication, the same point could be made for incomplete cycles with no search between a post-copula and the next copula.

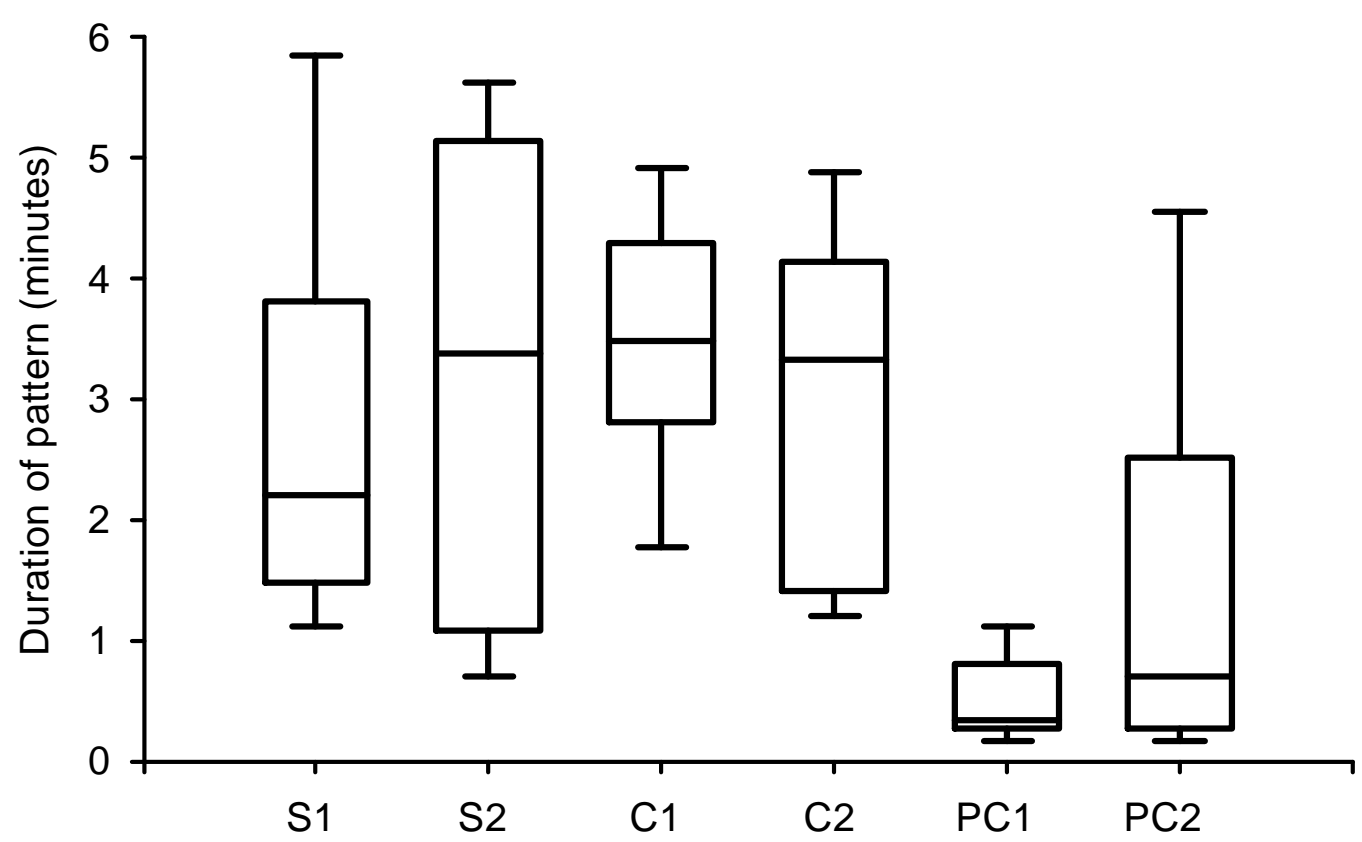

Fig. 2.1: Box-and-whiskers plots for the mating behaviour of Schizolachnus obscurus. $\mathrm{S}=$ searches, $\mathrm{C}=$ copulas, $\mathrm{PC}=$ post-copulas, $1=$ colonies with one male, $2=$ colonies with two males. Half the values fall within the boxes, which are divided at the median values. The whiskers extend to the 10 and 90 percentiles (all $\mathrm{N}=15$ ).

The median value of $C_{p k}$ was $6.16 \mathrm{~min}$ for colonies with one male (minimum: 2.20; maximum 10.05; $\mathrm{N}=15$ ) and 4.97min for colonies with two males (mini.: 1.62; maxi.: 44.22; $\mathrm{N}=15$ ). Hence, 5.6min should be a fair estimate of $C_{p k}$ in $S$. obscurus. Table 2.2 summarises the averages of search time and copula duration in the independent data set.

Table 2.2: Values of search time and copula duration from the independent data set

\begin{tabular}{lrr}
\hline Males per colony & 1 & 2 \\
\hline Search time $S$ & $1.31(0.32 ; 3.95 ; \mathrm{N}=6)$ & $1.77(1.07 ; 4.38 ; \mathrm{N}=9)$ \\
Copula duration $C$ & $2.18(1.33 ; 3.02 ; \mathrm{N}=2)$ & $3.34(2.62 ; 4.05 ; \mathrm{N}=2)$
\end{tabular}

The median is given with minimum and maximum in parentheses (all values in minutes). 
The observed search time of $1.31 \mathrm{~min}$ in colonies with one male would predict an optimal copula duration of $2.74 \mathrm{~min}$, whereas one of $2.18 \mathrm{~min}$ has been observed. Likewise, the observed search time of $1.77 \mathrm{~min}$ in colonies with two males would predict an optimal copula duration of $3.02 \mathrm{~min}$, whereas one of $3.34 \mathrm{~min}$ has been observed. The difference between these predictions for colonies with one and two males, however, is only $0.28 \mathrm{~min}$ or $17 \mathrm{sec}$.

\section{Discussion}

The second (independent) sample for testing the approximate marginal value model of Parker \& Stuart (1976) was tantalisingly small, especially the number of copulas. The ratio of observation/prediction was 0.80 for colonies with one male and 1.11 for colonies with two males. Hence, the fit between model predictions and observations could probably be largely improved by increasing this sample. Nevertheless, the apparently strange finding that copula duration did not increase along with the search time can be explained by the model. The difference in copula duration between colonies with one and two males is probably too subtle to be detected in the 'noisy' field data. The search times would need to differ two-fold or more, in order to produce appreciable differences in copula duration.

The doubling in post-copula duration is not due to a general increase from 0.33 to 0.70 minutes, or 19 to 42 seconds, as the averages would suggest. The frequency of mate guarding increased and the frequency of simply dismounting, which does take a while in clumsy aphids, decreased instead. Hence, male S. obscurus seem to be more likely to guard in colonies with competitors. The fact that guarding was not a regular feature performed after each copula is probably due to the strongly female biased sex ratio in this species. 


\section{Appendix}

\subsection{The model of G.A. Parker and R.A. Stuart}

A male should depart from a female when the gain rate in fertilised eggs drops to the average gain rate for the habitat (Parker \& Stuart 1976). In Scatophaga stercoraria L., males ensure their reproductive success by guarding females after copulation, while she is laying eggs. Hence guarding time is a reproductive effort expended on the eggs of the guarded female (see Birkhead \& Parker 1997, p. 131). Nevertheless, guarding time is conventionally added to the time spent searching for females ever since Parker \& Stuart (1976, p. 1060) claimed:

"The mean search cost $S$ for a new female is approximately $140 \mathrm{~min}$ (Parker 1970b), to which must be added the 16.5 min guarding time during oviposition."

This convention is warranted by the model's assumption that mate guarding can be treated as a constant (Geoffrey Parker and Kate Lessells in personal communications). Hence biological and modelling intuitions can easily clash about this question, and post-copula duration should not be assumed to be constant a priori (see chapter 2).

Parker \& Stuart (1976) fitted a gain function to data from sperm competition experiments with $S$. stercoraria: Males were allowed to copulate with previously mated females for different periods of time (Parker 1970a). One of the two males was radioactively marked and the proportion of eggs fertilised by the second male was determined. This paternity of the second is called the $P 2$ value. An exponential curve turned out to provide the best fit to these data (Parker \& Stuart 1976). A perpendicular dropped from the point where the tangent through $-S$ meets the gain function indicates the optimal solution (see fig. 2.2). 


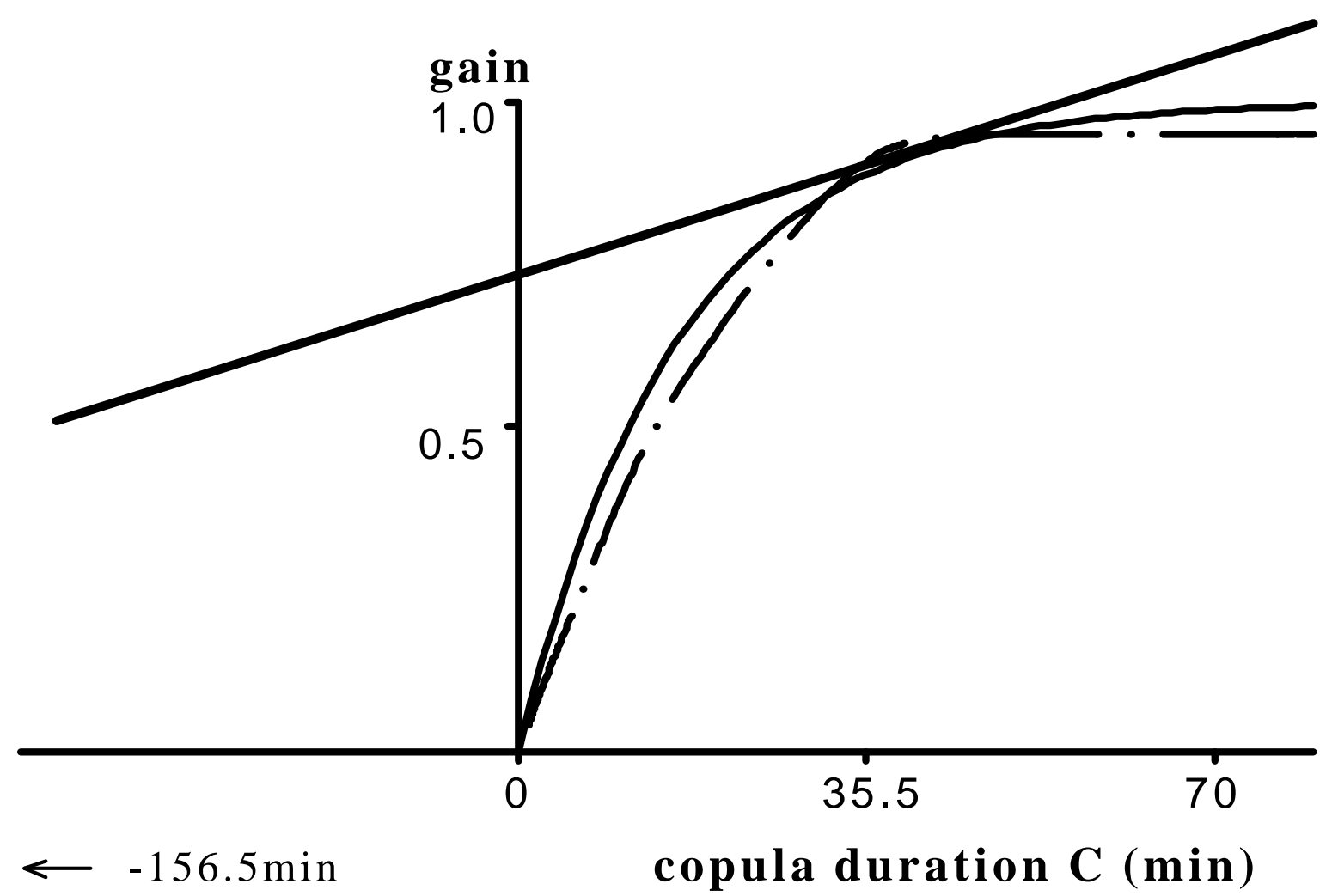

Fig. 2.2: Marginal value theorem as applied to mating behaviour of $S$. stercoraria. The solid curve gives best exponential fit $\left[\mathrm{G}=1-\mathrm{e}^{-\mathrm{C} / 16} ; \mathrm{C}_{\mathrm{opt}}=41.4 \mathrm{~min}\right]$ to $\mathrm{P} 2$ data from Parker (1970a). The dotted curve is an approximation that is parabolic $\left[\mathrm{G}=\left(0.95 \mathrm{C} / 45^{2}\right)(90-\mathrm{C}) ; \mathrm{C}_{\mathrm{opt}}=39.9 \mathrm{~min}\right]$ for $\mathrm{C}<45 \mathrm{~min}$ and constant $[\mathrm{G}=0.95]$ for $\mathrm{C}>45 \mathrm{~min}$. The tangent $[\mathrm{Y}=0.0047 \mathrm{X}+0.7313]$ runs through the point $[-156.5 \mathrm{~min} / 0]$ and touches the gain function at the point [41.4min/0.9248]. 


\section{Sex ratios and mate guarding*}

In aphids, sex ratios are quite variable ranging from extremely female biased to even ones; a few cases of male biased sex ratios have also been reported (e.g., Galli 1998, Dixon 1998). Dixon (1998, p. 97) suggested that copula duration could function as a means of guarding in aphids and showed that copula duration and sex ratio are correlated. In some aphid species, however, males also guard their mates after copulation. This is the case for Euceraphis betulae Koch. After copulation, the female bends its ovipositor downwards and touches the ground with the end of it, while the male remains mounted. In Uroleucon cichorii (Koch), however, the males simply leave the females after copulation. Hence, the mating behaviour of these species differs qualitatively.

$E$. betulae is a comparably slender and agile aphid species that lives on the leaves and young twigs of the birch, Betula pendula Roth. The parthenogenetic morphs are always winged and apt flyers, while the sexual females have no wings. The tendency to form colonies is comparably weak in this species. Individuals on one leave tend to keep their distance rather than to aggregate with close body contact. U. cichorii lives on hawksbeard, Crepis tectorum L. The animals are comparably plump and tend to form colonies. As typical for aphids, their parthenogenetic individuals are wing dimorphic and remain wingless under favourable conditions. Here, we compare the numerical sex ratios of these aphids with one another and with the ones given by Dixon (1998, p. 97).

\section{Methods}

In autumn 2000, the sex ratio of E. betulae was recorded from the accessible twigs of three birch trees of an estimated height of 10 meters standing on the northern campus of the University of Göttingen. The sex ratio of $U$. cichorii was recorded from the flowering hawksbeard plants in a weed fallow next to the campus. These samples were treated as cohorts and records were repeated on a weekly basis, one species being sampled on the following day of the other. Hence, the subsequent data values for one species depend on the previous ones of that species, but not of the other. Additionally, the data of Dixon (1998, p. 97, fig. 5.6) were reproduced and plotted with Sigma Plot. The positions of E. betulae and $U$. cichorii are indicated in this graph, from their sex ratios averaged over the first four samplings, and from sporadic observations of their copula duration.

\footnotetext{
* in press with S. Vidal, Proceedings of the 6th International Symposium on Aphids in Rennes, 3.-7.9.2001
} 


\section{Results}

The sample sizes of the cohorts reflect the collapse of aphid populations in autumn (fig. 3.1). In summer, of course, one would not find any adult sexual animals and neither in winter.

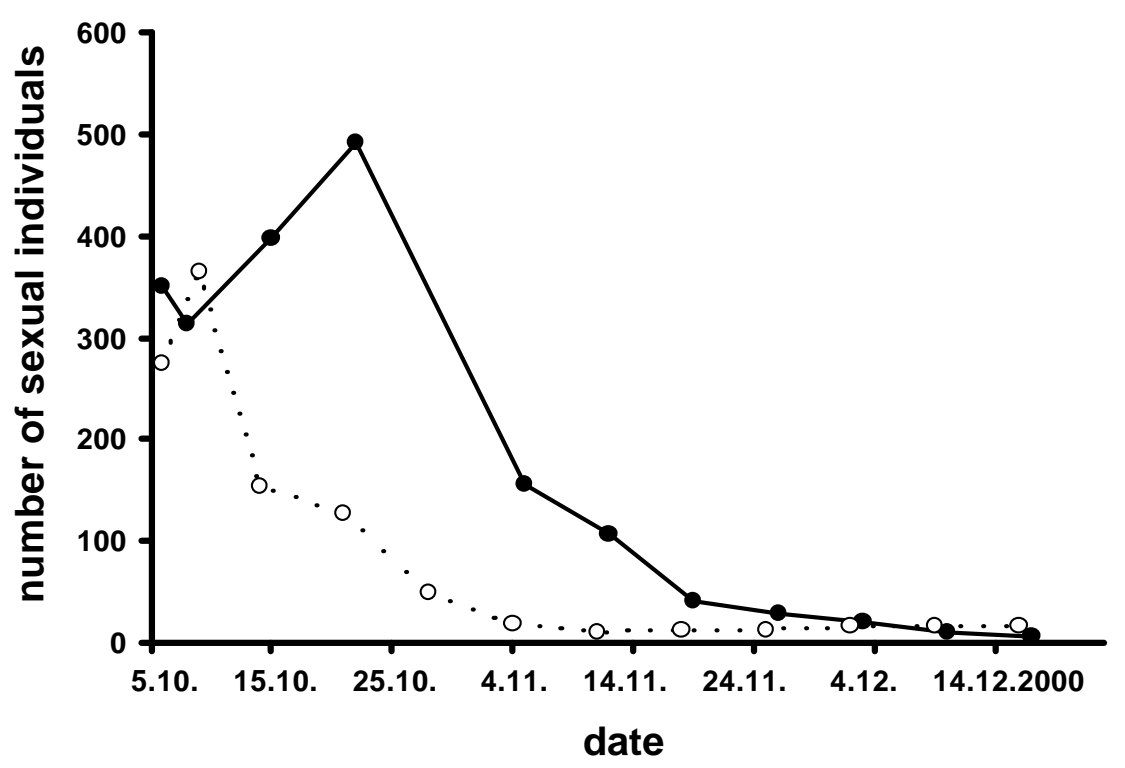

Fig. 3.1: Sample sizes for E. betulae (closed dots) and U. cichorii (open dots) during the sampling period.

The sex ratios of $E$. betulae and $U$. cichorii differed significantly during the first four samplings (table 3.1). E. betulae, the species with mate guarding males, also had the higher portion of males (fig. 3.2). Due to gales, the fifth sampling is missing for E. betulae. Crosstabulating the number of 128 females and 27 males of E. betulae at the sixth sampling against 47 females and 2 males of $U$. cichorii at the fifth sampling still yields a significant difference $\left(\chi^{2}=5.431, \mathrm{p}=0.02,1 \mathrm{df}\right)$. At the sixth sampling, however, the sample size of $U$. cichorii had already dropped to 17 females and 1 male and was henceforth too small for testing by Pearson's $\chi^{2}$, and was insignificant by Fisher's exact test anyway.

Table 3.1: Cross-tabulations of the numbers of males and females in E. betulae and $U$. cichorii

\begin{tabular}{lllll}
\hline sampling & dates & Pearson's $\chi^{2}$ & $\mathrm{p}$ value & $\mathrm{df}$ \\
\hline $1^{\text {st }}$ & 6.10. & 20.326 & $<.001$ & 1 \\
$2^{\text {nd }}$ & $08 .-09.10$. & 39.995 & $<.001$ & 1 \\
$3^{\text {rd }}$ & $14 .-15.10$. & 37.822 & $<.001$ & 1 \\
$4^{\text {th }}$ & $21 .-22.10$. & 29.884 & $<.001$ & 1 \\
\hline
\end{tabular}


An exceptionally late male E. betuale occurred at the $10^{\text {th }}$ of December, whereas no males have been found before or after that date. In combination with the low number of 7 females, this male caused an exceptionally high portion of males. Both E. betulae and $U$. cichorii are situated in the middle of the graph (fig. 3.3) that has been reproduced from Dixon (1998, p.97).

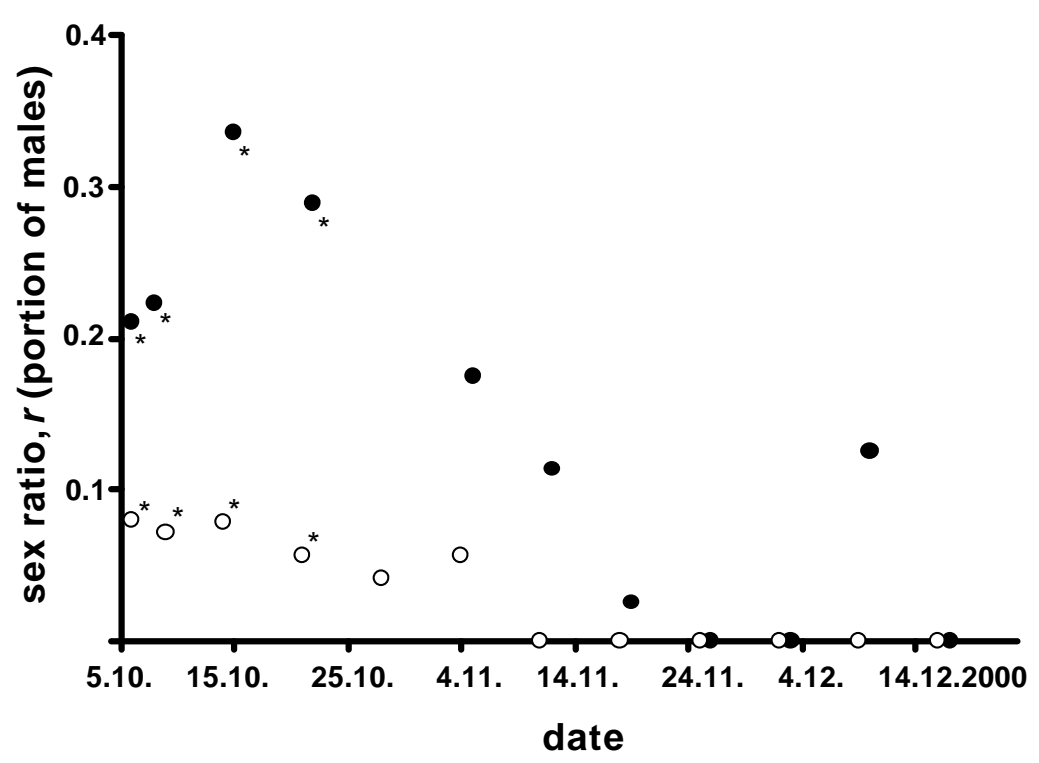

Fig. 3.2: Numerical sex ratios of E. betulae (closed dots) and U. cichorii (open dots). Pearson's $\chi^{2}$ values for cross tabulations of the first four samplings were highly significant $(*: p<.001)$.

\section{Discussion}

As expected, the sex ratio of the mate guarding E. betulae was less female biased than the one of the not guarding U. cichorii. All parthenogenetic morphs of E. betulae are winged and apt flyers, while the tendency to disperse is comparably high in this species. U. cichorii, however, tend to aggregate and parthenogenetic morphs are wingless under favourable conditions. Hence, the mixing of individuals stemming from different clones should be better in $E$. betulae, and consequently the degree of local mate competition should differ in both species. Male E. betulae probably experience less kin competition for females than male $U$. cichorii. This inference from general habits agrees with the finding of the more female biased sex ratio in $U$. cichorii, because local mate competition should bias the sex ratio towards females (Hamilton 1967). A female biased sex ratio, in turn, will lift the pressure for mate guarding, while selecting for higher polygamy of males.

The fact that male E. betulae guard their males after copula, but male $U$. cichorii do not, invites an interesting conjecture. A transition of mating behaviour might occur as sex 
ratios change from small to large portions of males. If this was true, aphid species with more than 13 females per male should not feature post-copula mate guarding, while males from species with less than 3 females per male should guard or copulate for longer than necessary for fertilisation or both.

In this respect, a comparison with the data provided by Dixon $(1998$, p. 97) is also interesting. The sex ratios of E. betulae and $U$. cichorii roughly fall towards the left and right of the middle range (between 0.4 and 1.0) of figure 3.3. The copulas in these species last for minutes, while the two extremes that are measured in hours (above 0) fall to the left and the two extremes that are measured in seconds (below -1.8) fall to the right.

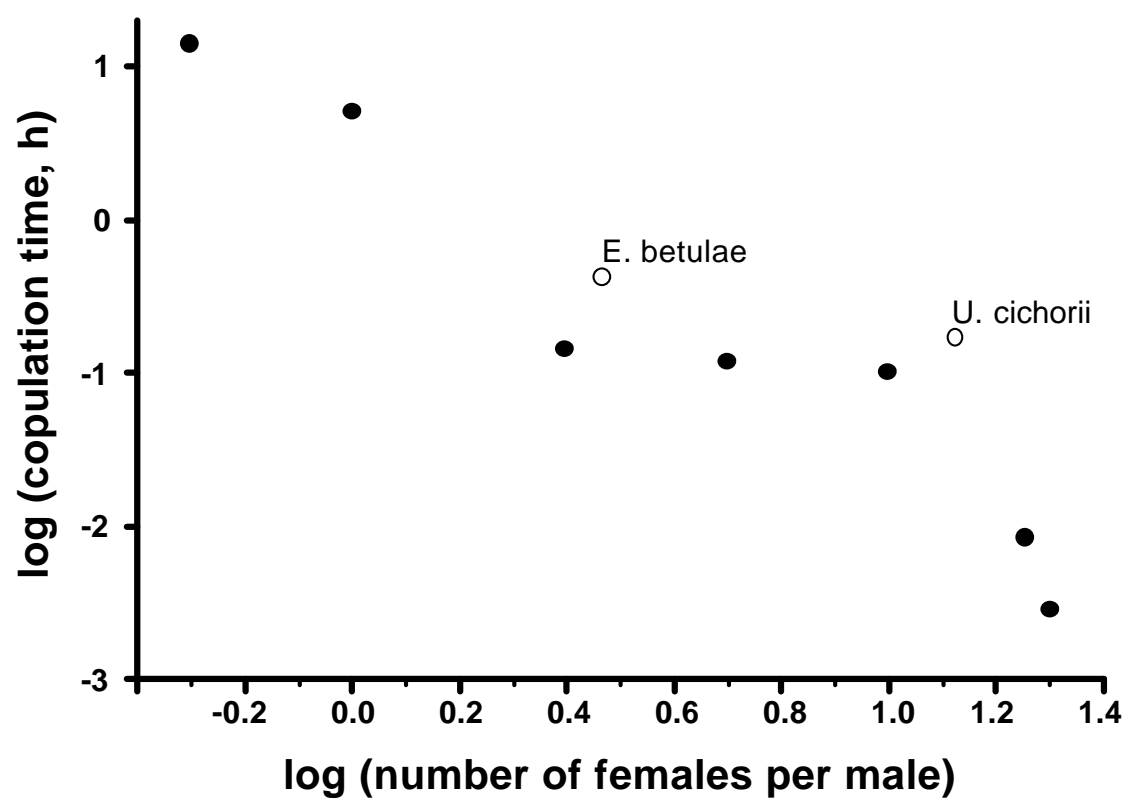

Fig. 3.3: Graph of data reproduced from Dixon (1998, fig. 5.6) also indicating the positions of E. betulae and $U$. cichorii. Unfortunately, the species identities and literature sources for the other data points are not known. 


\section{Appendix}

\subsection{Patterns of mating behaviour other than guarding}

Pre- or post-copula behaviour is not necessarily mate guarding. Pettersson (1968) pioneered the study and discovery of the female 'calling' pheromone in aphids, but also described a 'courtship' for Schizaphis dubia Huc. and S. borealis Tambs-Lyche: "Something that might be a male courtship was seen shortly before the copulation, always following the same pattern. The male investigated the dorsal side of the female with its antennae and rostrum.

The antennae were then bent downwards and stretched close to and along the antennae of the female (fig. 1b). This "courtship" lasted as a rule for some minutes and after this a normal copulation was performed (fig. 1c).” (Pettersson 1968, p. 361)

Interesting descriptions of mating behaviour in aphids are far older than Pettersson's (e.g., Bonnet 1779, p. 68). Commenting on Bonnet, who described Stomaphis quercus (L.) in a non-Linnéan style, Buckton (1876, p. 53) wrote: "He gives a ludicrous account of the wooing, which was accompanied by a rapid vibration of the antennae and oscillation of the legs of the insect." All morphs of St. quercus, however, rotate their backwards pointing antennae. This might increase the attention of ants, usually Lasius fuliginosus (Latreille), which is obligate for this species. Goeze (1774) has translated essays from Bonnet and other naturalists into German including one of de Geer (1755). Probably describing Brachycaudus helichrysi (Kaltenbach) in a non-Linnéan style, de Geer describes the 'courtship' of a male aphid on plum leaves in great detail. The male, however, left three females before copula eventually copulating with the fourth (in Goetze 1774, p. 389). This falsifies Buckton's (1876, p. 56) claim about de Geer that: "Except in a slight and general way he does not investigate the phenomena connected with the impregnation of Aphides." It might even be the first description of mate choice in aphids.

According to Eberhard (1998), the apparently strange antics that are often associated with courtship (e.g., licking, tapping, rubbing, kicking, stroking, shaking, squeezing, feeding, singing to, and vibrating the female during copulation) are signals for the females that have evolved under cryptic female choice for reliable signalling. A female aphid, for example, might receive the information that the insect on her back is a con-specific male rather than a foreign male, ant, or parasitoid from courtship occurring before copulation and that the mating is over from courtship occurring after copulation. This, however, does not exclude the possibility that later males also gather information from traces of previous mating.

Dagg \& Scheurer (1998) have described a peculiar courtship in Cinara cuneomaculata 
(DelGuercio). The male sits with its head over the thorax of the female before copulating. Copulation is impossible in this position, because females have much larger abdomina than males, and he needs to move backwards into copula-position. Male C. cuneomaculata stroke the ventral side of the female with the hind tibiae during copulation. Thereafter he strokes the female's dorsal side with his penis in a zig-zag movement, while moving forward on top of the female. The male's large wings 'amplify' this zig-zag movement of his abdomen.

While this might be a case of male signalling under cryptic female choice, it is not unlikely that it also leaves traces on the female which could be perceived by following males. Sexual females of $C$. cuneomaculata have a so-called 'pre-anal wax ring' that extends from the base of the siphonae to the end of the body on the dorsal side and covers the ventrum (neither parthenogenetic nor juvenile sexual females have a wax ring). Its white colour contrasts sharply with the rest of the dark brown body. This 'wedding dress', however, looks rather worn in egg laying females. It is not unlikely that the leg and penis stroking of male $C$. cuneomaculata blurs this wax ring leaving traces of mating on the female. At the same time, C. cuneomaculata lives in facultative association with ants raising the question whether ants blur the wax ring differently than males and whether males can perceive the difference.

Males of the taxon Lachnidae Herrich-Schaeffer including the genus Cinara Curtis cannot retract their penis into the abdomen, whereas males of other aphid taxa retract their penis into the abdomen immediately after copulation and often do not feature striking postcopula courtship (e.g., U. cirsii). Unlike Lachnidae, however, aphids of the taxon Aphidinae Baker have eversible membranes at the end of their tibiae with which they can walk upside down on a clean glass surface (Dixon et al. 1990). Adhesion is effected by the tension between the glass surface and the sponge-like pads that contain adhesive fluid (Dixon et al. 1990). Furthermore, waxy covers are common throughout aphids. It is therefore not unlikely that males of other species will also leave traces of their mating on the females. Whether such traces also inform subsequent males is a question that should be addressed. 


\section{Kin competition and differential sex ratios ${ }^{*}$}

Asymmetries in competition among males on the one hand and among females on the other select for sex ratio shifts towards the sex with the higher fitness prospects (Frank 1986). If, for example, males were more likely to suffer from kin competition than females, the overall sex ratio in the breeding population should be female biased on average (Hamilton 1967). If the fitness prospects of males depended stronger on the condition of their mothers than the fitness prospects of females, individual mothers should differentially produce more male offspring with improving condition, even if the overall sex ratio in the breeding condition remained even on average (Trivers \& Willard 1973).

Aphids are particularly suitable objects for studying these effects of asymmetric competition on diploid organisms, because of their widely varying sex ratios, their phenotypic plasticity, and their various life cycles. Phenotypic plasticity provides variance in maternal condition (e.g., size or fertility) even among animals of the same clone. The various life cycles lead to different forms of sex-biased dispersal and hence sex-biased kin competition. Aphids reproduce asexually through ameiotic parthenogenesis during spring and summer followed by one bout of sexual reproduction in autumn (cyclic parthenogenesis).

Yamaguchi (1985) has studied the pemphigin aphid Prociphilus oriens Mordvilko. In this species, the mothers of the sexual generation (sexuparae) are winged and migrate from the summer to the winter host before giving birth to wingless sexual females and males. If population density is low and most colonies are formed by single sexuparae, this will entail a high degree of kin competition among males. Therefore, sexuparae should produce sons up to a level sufficient to fertilise all females possibly arising in a breeding patch (Yamaguchi 1985). Indeed, Yamaguchi (1985) found a constant investment into sons, while investment into daughters varied differentially with maternal condition, as predicted by her model. May \& Seger (1985) have criticised her assumption that the mothers of the sexual generation allocate their offspring sex ratio, because development of the sexual individuals already starts while their mothers are still embryos (telescoping of generations). Therefore, Kindlmann \& Dixon (1989) had to suggest a different proximate mechanism of sex allocation acting on the grand-maternal generation instead. Foster \& Benton (1992) have also found a strongly female biased sex ratio in Pemphigus spyrothecae Pass which has an identical life cycle.

At high population densities, however, kin competition between males will be less

\footnotetext{
* submitted with C. Rispe and S. Vidal to Behavioral Ecology and Sociobiology
} 
intense, because many sexuparous females (mothers) will found colonies on the winter host in groups. In this situation, resource competition between sexual females or their offspring might become limiting. The latter is very likely in this group of aphids, because the sexual females lay their eggs into crevices (Kindlmann \& Dixon 1989) and the parthenogenetic females hatching in spring induce galls. Galli (1998), for example, found male biased overall sex ratios in the species Tetraneura nigriabdominalis (Sasaki) belonging to the Pemphiginae.

In species with dimorphic host alternation, males and sexual females migrate independently to the winter host; the males as winged adults, the sexual females as embryos inside their mothers (a special morph called gynopar). Local mate competition between closely related males should be prevented by the mixing of winged males during host alternation. This life cycle has been taken to mean an even investment into both sexes in the sense of Fisher (1930), because out-breeding is ensured by the dimorphic host alternation (e.g., Newton \& Dixon 1987; Ward \& Wellings 1994; Dixon 1998, p. 94). For the sexuparae, that produce males and gynoparae in this case, a male will cost far more than a sexual female because sexual females are set off as embryos inside their gynoparous mothers. If males and gynoparae were equally expensive in terms of resource investment, for example, but each gynopara gave birth to nine sexual females on average the overall portion of males should be $1 / 10$. In this way, the strongly female biased sex ratios would nevertheless constitute a case of even sex allocation (e.g., Ward \& Wellings 1994). A lack of resource competition among sexual females or their offspring cannot be taken for granted, however, because sibling sexual females 'travel' together and are wingless.

Here we report on differential sex allocation in an aphid species that does not alternate between summer and winter hosts. It is generally not known whether winged males of such species mate on patch before taking the risk of long distance flight or not. Our data on differential sex ratios agree with the model predictions by Yamaguchi (1985) for kin competition among males. This will be compared with evidence on an aphid species with dimorphic host alternation (migrating males and gynoparae) that has already been published (Rispe et al. 1999), but has not been interpreted in terms of differential sex allocation theory. These results support the idea that an asymmetry in kin competition between sexual females or their offspring prevails despite the out-breeding life cycle. This expands and refines the model by Ward \& Wellings (1994) by including competition among females. 


\section{Methods}

Uroleucon cirsii (L.) is a large aphid and lives on the creeping thistle, Cirsium arvense (L.) Scop. Its sexual generation consists of winged males and wingless females. The gender of a nymph can be easily determined, because males are leaf-green, while females are chocolate brown. No asexual or intermediary clones (e.g., producing parthenogenetic females plus males) are known.

Five individuals from one clone of $U$. cirsii continually bred under long day conditions were transferred onto a potted plant and into short-day conditions (12D:12L at $14^{\circ} \mathrm{C}$ ), in order to induce sexual reproduction. When in fourth instar, descendants (mothers) were transferred onto excised leaves whose cut ends had been inserted into watered floral foam inside plastic boxes $(45 \times 80 \times 30 \mathrm{~mm})$ fitted with a gauze-sealed opening for ventilation. Of the 12 mothers chosen at random, one lost a fore leg during handling. Because this female's condition was obviously abnormal, we excluded her data from analysis. The weight and the numbers of sons and daughters were recorded every $24 \mathrm{~h}$ for each mother starting with the first day of reproduction.

Maternal condition was either estimated as her weight or the number of her offspring. Because a mother's weight varies widely on a day-to-day or hour-to-hour basis (probably because of sudden reductions in weight through birth), maternal weight has to be averaged over a period of reproductive adult life. We favoured a 12-day period, because the first mother died during the $13^{\text {th }}$ day.

In Rhopalosiphum padi (L.), males and gynoparae (containing the sexual females) migrate independently to the winter host Prunus padus L. We reanalyse in this paper published data from Rispe et al. (1999, table 4), which were not discussed in the theoretical context of differential sex allocation with variable maternal condition. The number of males and gynoparae (daughters) are our dependent variables and the number of offspring (gynoparae + males) is the independent variable as a measure of maternal condition. Unlike our data for $U$. cirsii, the data of Rispe et al. (1999) does not give differential sex allocation between mothers of one clone, but differential sex allocation between 27 different sexual clones. The data points are averages of 8 to 19 mothers from each clone. Experimental methods for R. padi are described in Rispe et al. (1999). 


\section{Results}

\section{Uroleucon cirsii}

In $U$. cirsii, males are neither born first nor last but are interspersed with sexual females. As illustrated in figure 4.1, most of the offspring are born within the first ten days of reproduction. The pattern illustrated in figure $4.2 \mathrm{a}$ remained stable from the seventh day of reproduction onwards. The number of sons is neither influenced by mean maternal weight over the first 12 days of reproduction $\left(\mathrm{r}^{2}=0.021, \mathrm{~F}_{1,9}=0.195, \mathrm{p}=0.669\right)$ nor over the whole reproductive period $\left(\mathrm{r}^{2}<0.001, \mathrm{~F}_{1,9}=0.001, \mathrm{p}=0.974\right)$. However, the number of daughters increases significantly with maternal weight during 12 days $\left(\mathrm{r}^{2}=0.678, \mathrm{~F}_{1,9}=18.926, \mathrm{p}=\right.$ $0.002)$ and over the whole period of reproduction $\left(r^{2}=0.506, F_{1,9}=9.216, p=0.014\right)$.

When the number of offspring (daughters + sons) is taken as an estimate for maternal condition instead of weight, this pattern is not altered (fig. 4.2a). Again, the number of sons is independent of maternal condition over the first 12 days $\left(r^{2}=0.035, F_{1,9}=0.328, p=0.581\right)$ and the whole phase of reproduction $\left(r^{2}=0.038, F_{1,9}=0.360, p=0.563\right)$, whereas the number of daughters increases significantly with improving maternal condition over 12 days $\left(\mathrm{r}^{2}=\right.$ $\left.0.830, \mathrm{~F}_{1,9}=43.847, \mathrm{p}<.001\right)$ and the whole reproductive period $\left(\mathrm{r}^{2}=0.931, \mathrm{~F}_{1,9}=120.971, \mathrm{p}\right.$ $<.001)$. The mothers of this species showed a constant numerical investment in sons, whereas the investment into daughters increased with maternal weight or fecundity (table 4.1). This pattern was stable from the 7 th day onwards.

\section{Rhopalosiphum padi}

The number of sons increased strongly and significantly with improving maternal condition $\left(r^{2}=0.845, F_{1,25}=135.830, p<0.001\right)$. Nevertheless, the regression slope for gynoparae was also slightly positive and significant $\left(\mathrm{r}^{2}=0.150, \mathrm{~F}_{1,25}=4.420, \mathrm{p}=0.046\right)$. This pattern of differential sex ratios is illustrated in figure $4.2 \mathrm{~b}$. We also performed a linear regression for the difference between the number of males and gynoparae of each clone against maternal condition as the independent variable (table 4.1). This regression indicated a significant difference between the slopes for males and gynoparae (cf. fig. 4.2b) respectively $\left(r^{2}=0.477\right.$, $\left.\mathrm{F}_{1,25}=22.812, \mathrm{p}<0.001\right)$. The same general trend, a strong increase in sons and a weak one in daughters with improving maternal condition, could be found within clones (C.R. unpublished data). 


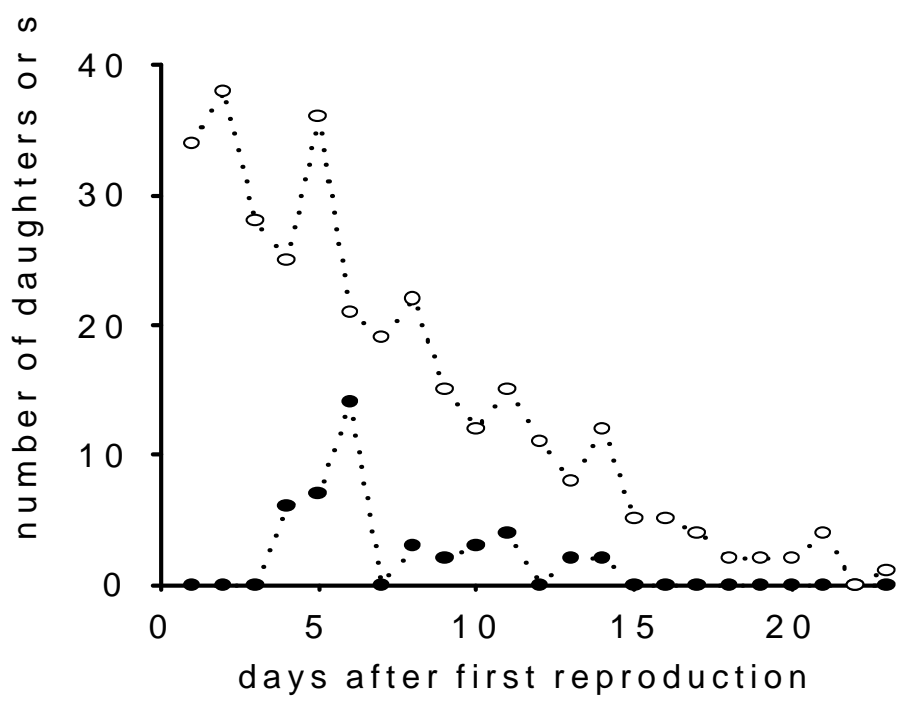

Figure 4.1. Sum of daughters or sons born on each reproductive day by all mothers of $U$. cirsii taken as a cohort. Open symbols are daughters and closed symbols are sons.

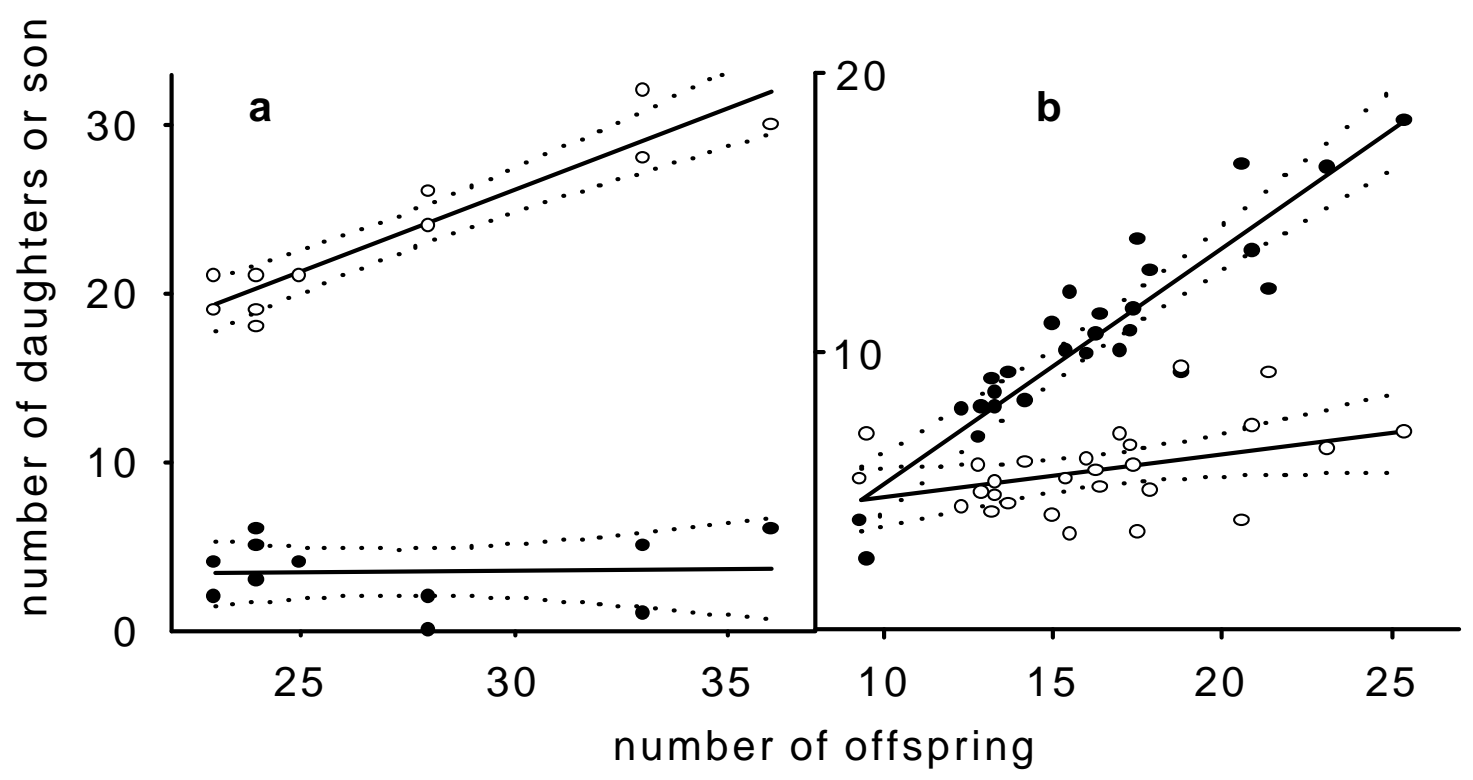

Figure 4.2. Differential sex ratios. a $U$. cirsii: number of offspring per mother during the period of the first 12 days of reproduction $\left(\mathrm{Y}_{\text {(daughters) }}=-1.304+0.920 \mathrm{X} ; \mathrm{Y}_{\text {(sons) }}=1.304+0.080 \mathrm{X}\right)$. Open symbols are daughters and closed sons. $\mathbf{b}$ R. padi: number of offspring with each data point representing the average from 8 to 19 replicates of clonally identical mothers $\left(\mathrm{Y}_{\text {(gynopara) }}=3.217+0.153 \mathrm{X} ; \mathrm{Y}_{\text {(males) }}=-3.217+0.847 \mathrm{X}\right)$. Open symbols are gynoparae and closed symbols males. 
Table 4.1. Differential maternal sex allocation of $U$. cirsii and $R$. padi

\begin{tabular}{lrrrrr}
\hline independent variable & offspring & coefficient $\beta$ & SE & t & $\mathrm{p}$ \\
\hline \multirow{2}{*}{ In $U$. cirsii: maternal condition measured as mean weight over } & & & \\
$1^{\text {st }} 12$ reproductive days & sons & 0.61 & 1.38 & -0.44 & 0.669 \\
& daughters & 8.17 & 1.88 & 4.35 & 0.002 \\
whole reprod. period & sons & -0.07 & 2.04 & -0.03 & 0.974 \\
& daughters & 16.97 & 5.59 & 3.04 & 0.014 \\
\hline
\end{tabular}

In $U$. cirsii: maternal condition measured as offspring number over

\begin{tabular}{lrrrrr}
$1^{\text {st }} 12$ reproductive days & sons & 0.08 & 0.14 & 0.57 & 0.581 \\
& daughters & 0.92 & 0.14 & 6.62 & $<.001$ \\
whole reprod. period & sons & -0.06 & 0.10 & -0.60 & 0.563 \\
& daughters & 1.06 & 0.10 & 11.00 & $<.001$ \\
\hline
\end{tabular}

In R. padi: maternal condition measured as offspring number over

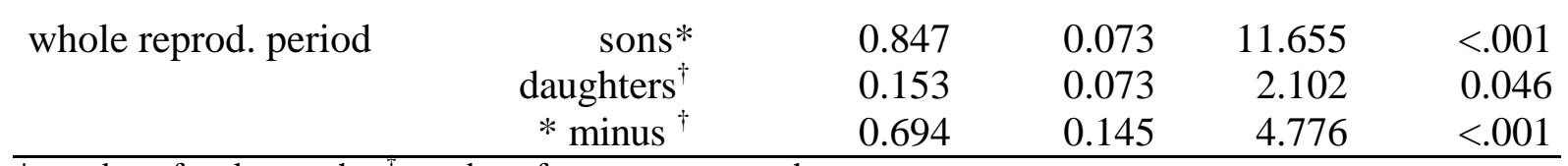

* number of male morphs, ${ }^{\dagger}$ number of gynoparous morphs

\section{Discussion}

\section{Uroleucon cirsii}

Our results for $U$. cirsii agree with the predictions for kin competition between males (Yamaguchi 1985). Competition between closely related males could result from two factors. Males could mate and compete for females within the colonies they emerge from before taking off for long-distance flight (partial local mate competition) or experience some competition from clonally related males even after flight (clonal mate competition) or both. Cases of partial local mate competition are known from parasitic and parasitoid wasps (e.g., Hardy 1994; West \& Herre 1998; Debout et al. 2002). The hypothesis of partial local mate competition seems to be plausible, because of the high mortality during flight. Clonal mate competition would be likely, if clones were large or dispersal ineffective. As the pattern of differential sex ratios illustrated in figure $4.2 \mathrm{a}$ remained stable from the $7^{\text {th }}$ day of reproduction onwards, after the first peak if male births (cf. fig. 4.1), birth order and longevity seem to be irrelevant for the result.

\section{Rhopalosiphum padi}

Our data agree best with the predictions for kin competition between sexual females or their offspring. This is plausible, because the sexual females, which are born by gynoparae, are 
wingless and do not move far from their birth place. Sexual females might be limited by places for oviposition and compete with their clonal sisters for them. Alternatively, the offspring of the sexual females and the colonies founded by them might compete for resources in spring. The females that hatch from eggs in spring induce leaf curling possibly exacerbating resource competition between neighbouring colonies that way. In $R$. padi, mortality in spring is indeed dependent on density in autumn (C.R., unpublished data). Nevertheless, kin competition among sexual females is probably not absent in $U$. cirsii. In $R$. padi, however, no kin competition among males can override this resource competition among related sexual females because the males disperse before mating.

The significantly positive slope for gynoparae might be due to the complex life cycle under study. The chance of a gynoparous female to survive host alternation could be related to her mother's condition though less strongly than in males. In this case, the investment into gynoparae should also increase with improving maternal condition. In $R$. padi, males are not born interspersed but after gynoparous females (Dixon \& Glen 1971) suggesting a role of birth order and survival time of the mothers in the sex ratio. This has been proven for another aphid species with identical life cycle, Myzus persicae (Sulzer), by Hales et al. (1989). Therefore, accidental shortening of survival time will impinge more on the number of males than the number of gynoparae born. Tony Dixon (pers. comm.), however, pointed out that the numbers of gynoparae born by the clones of Rispe et al. (1999) were generally much lower than those found by Dixon \& Glen (1971). This suggests differences in the condition of the animals, their host plants, or the climatic factors used for induction of sexual reproduction. It should, therefore, be useful to correlate offspring number to maternal weight in $R$. padi and check whether the slopes of the linear regressions for gynoparae and males can be extrapolated to ranges above the ones depicted in figure $4.2 \mathrm{~b}$ extending to the ones found by Dixon \& Glen (1971).

Another complication to be considered in this respect is the existence of clones that hardly produce any males on the one hand and asexual clones that also produce a few males in $R$. padi (Rispe et al. 1999; Delmotte et al. 2001). Including these clones into the consideration will make panmixis (random mating plus random competition) an even less likely assumption for $R$. padi. At the same time, kin competition between sexual females should prevail and males should be mixed during host alternation regardless of the clones they belong to. We admit that we do not hold the whole picture of differential sex allocation in $R$. padi, which is a highly complicated affair, but the key to understanding it might lie in including resource competition among females into the consideration. 


\section{Appendix}

\subsection{First instar weights of sexual females and males of $U$. cirsii}

A potted plant with five larval $U$. cirsii was transferred into short day conditions and left there in contact with three further potted plans onto which animals could migrate. First instar males of the F2 generation were collected daily together with the first instar females directly neighbouring them. The weight was measured with a micro-balance and recorded together with the sex. Because nymphs simply stay were they are born, collecting first instar males together with the neighbouring first instar females should be a suitable method to avoid systematic biases between the age of female and male nymphs after birth and before the first larval moult and hence their size.

A totalㄲf 34 males and 103 female first instar nymphs were collected and weighed. The mean weight of male nymphs was $150 \mu \mathrm{g}(32 \mu \mathrm{g})$ and that of females $122 \mu \mathrm{g}(40 \mu \mathrm{g})$ (SD in parentheses). This difference is significant (pooled variance $\mathrm{t}=-3.711, \mathrm{df}=135, \mathrm{p}<0.001$ ). Figure 4.3 gives the counts, density functions and box plots for both sexes.

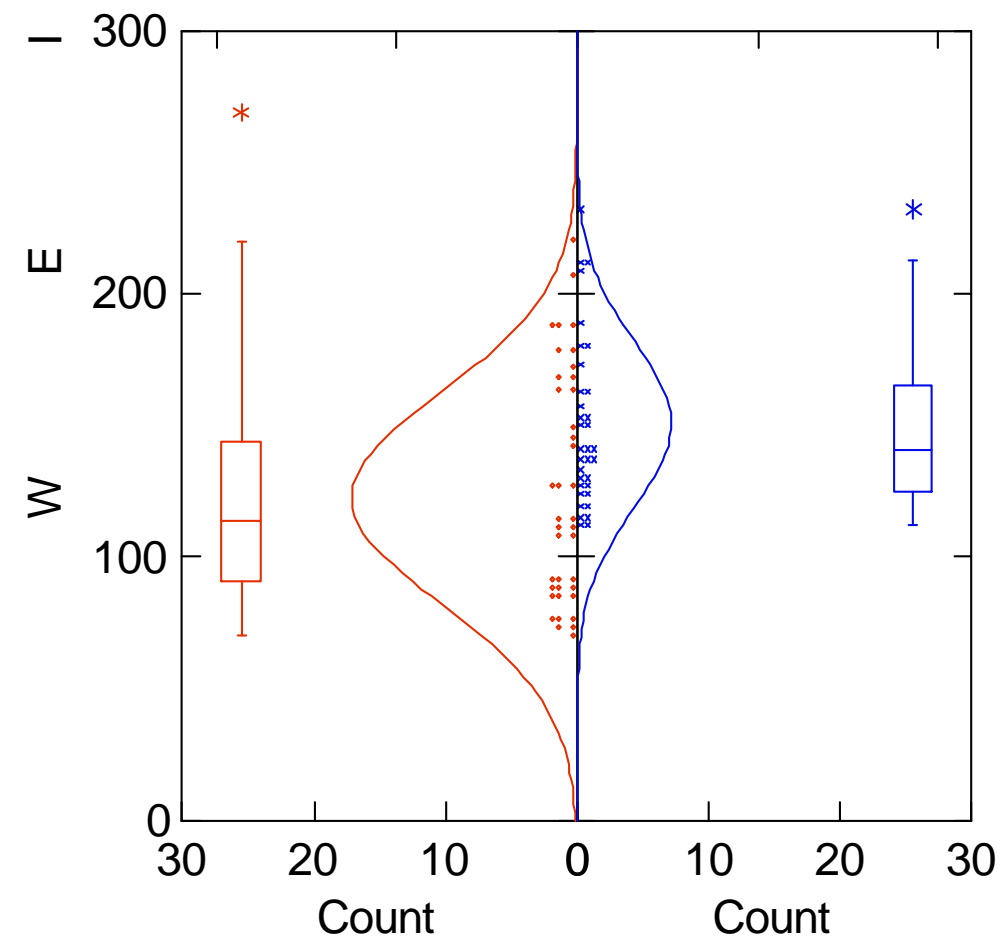

Fig. 4.3: Weight (in $\mu \mathrm{g})$ of first instar males and females. 
The average of $28 \mu \mathrm{g}$ that male first instar nymphs are heavier than females, however, does not suffice to compensate for the strongly female biased sex allocation in $U$. cirsii. The two mothers with the highest portion of sons, for example, had a life time reproduction of 6 sons in 30 offspring and 7 sons in 35 offspring respectively. Taking the above given averages as birth weights would result in investment ratios of $900 \mu \mathrm{g}: 2928 \mu \mathrm{g}$ and $1050 \mu \mathrm{g}: 3416 \mu \mathrm{g}$ (sons:daughters) respectively. After correction for birth weight, even the mothers with the highest proportion of males in their offspring invested more than three times as much in female offspring. Furthermore, the slopes of the linear regressions of differential sex allocation versus maternal condition will not be affected by such a correction for birth weight. The constant (horizontal) regression line for sons in figure 4.2a would only lie slightly closer to the steeply rising line for daughters.

Males of Drepanosiphum platanoides (Schrank) and Sitobion avenae (Fabricius) are also larger than females at birth (Dixon pers. comm.). If this should be a general feature of aphids, it would deserve a general explanation. Some working hypotheses to start from can already be formulated: Larger male nymphs might mature quicker and earlier adult males have some kind of advantage. Alternatively, larger nymphs might end up as bigger adults and be stronger competitors. Larval mortality might also affect reproductive success worse, if it occurred in the rare sex, and heavier nymphs might survive better. 


\section{Population density and the sex allocation}

The fewer the animals that found a breeding group the more intense the kin competition will be among their offspring. A model for the portion of sons $r$ among the offspring of $N$ founding mothers has be given by Hamilton (1967):

$$
r=\frac{N-1}{2 N} \text {. }
$$

The number of founding mothers $N$ is inversely related to the intensity of kin competition among the offspring. Substituting $N$ by $1 / F$ yields:

$$
r=\frac{1-F}{2}
$$

where $F$ is the probability that genes competing for loci in a zygote will be identical by descent. $F$ has been interpreted as the inbreeding coefficient (West et al. 2000, footnote 13), but it can as well be called the coefficient of kin competition at the genetic level. Hence $F$ is the probability that two genes competing for a place in a zygote are identical by descent. Hamilton's model predicts that single mothers will invest nothing into sons and the portion of males in its offspring will be zero. This should be taken to mean that single mothers should invest the minimum necessary to assure the fertilisation of their daughters into sons.

Nevertheless, it is difficult to see how an individual aphid could assess the size of the group of sexuparae it joins and their fecundirty. This difficulty is exacerbated by the so called telescoping of generations. The offspring of the sexuparae start to develop and their sex is determined, while their mothers are still embryos (May \& Seger 1985; Kindlmann \& Dixon 1989; Dixon 1998, p. 93). In fact, the statement that the sexuparous "mothers appear to have direct control over the sex ratios of their offspring and their fecundities over a wide range" (Yamaguchi 1985, p. 462) seems to be the main reason why Yamaguchi's model for sex allocation with differential maternal condition has not been well appreciated.

In $U$. cirsii, sex ratios vary with maternal condition in a way fitting to Yamaguchi's model (see above). This, however, does not mean that the proximate mechanism of sex allocation needs to lie within the sexuparae. Kindlmann \& Dixon (1989) have proposed a proximate mechanism of sex allocation in aphids working via population density. A high density during the grand-maternal generation with respect to the sexual females and males should have two effects: 1) Grandmothers should become smaller, giving birth to smaller sexuparae, which in turn will produce the same amount of sons but fewer daughters. 2) Sexuparae should be more abundant and hence more likely to found colonies together with other sexuparae. 
At low densities, sexuparae will be likely to remain single and thus kin competition among males should be high. At the same time, these sexuparae will be big and produce a lot of daughters. In result, local mate competition will be high and the portion of males low. At high densities, however, sexuparae will be numerous and likely to settle together, which reduces the overall intensity of kin competition. At the same time, these small sexuparae will produce fewer daughters resulting in less female biased overall sex ratio in the population of sexual animals. According to this model, the ultimate cause (kin competition) and the proximate cause (population density) of sex allocation are correlated but quite distinct. Natural selection is assumed to have seized on population density experienced by the grandmothers as an early (proximate) indicator for the likelihood of kin competition among the sexual females and males, which in turn is the ultimate cause of biased sex ratios. The following experiments test the effects of different densities at different generations on the sex ratio in $U$. cirsii.

\section{Methods}

Two nymphs of $U$. cirsii were taken from the continuous breed and transferred onto a potted plant under short day conditions $\left(12 \mathrm{~h}\right.$ light, $\left.14^{\circ} \mathrm{C}\right)$. From the offspring (sexuparae) fourth instar nymphs were chosen and apportioned into standard boxes with one or two individuals at random. Offspring number and sex was recorded daily, but nymphs were not removed from the boxes. The maximum number of sexual females recorded while the number of males was also at its maximum was chosen as the best estimate of the sex ratio in each box. In this experiment, the sexuparae experienced systematically different densities from their fourth instar onwards. This effect increased through the stronger crowding of the sexual offspring in boxes with two mothers. The second experiment was identical to the first, but crowding of the sexual offspring was excluded by taking the nymphs of the sexual generation out of the standard boxes each day. The daily offspring was sexed and their numbers added for each mother. Hence the sex ratios of this experiment give the portion of males of the total offspring produced by each mother. The third experiment was identical to the second in that nymphs were taken out of the boxes, after they have been counted and their sex recorded. However, the experimental groups did not differ in the number of sexuparous mothers per box, which was always one. This time, the number of nymphs that were transferred onto the potted plants under short day conditions was varied. Either five or one of these grandmothers of the sexual generation to be were transferred. The only systematic difference in density was the one experienced by the grandmothers and their daughters, the sexuparae, up to their fourth instar. 


\section{Results}

The sex ratios are summarised in table 5.1. The first experiment, one or two mothers per box, yielded no significant results $\left(\mathrm{U}=33, \mathrm{p}=0.508, \chi_{\text {approximation }}^{2}=0.439,1 \mathrm{df}, \mathrm{N}_{1}=9, \mathrm{~N}_{2}=9\right)$. The same was true, if the new born larvae were taken out of the boxes each day $(\mathrm{U}=110, \mathrm{p}=$ $0.826, \chi_{\text {approximation }}^{2}=0.048,1 \mathrm{df}, \mathrm{N}_{1}=14, \mathrm{~N}_{2}=15$ ). Variable densities at the grand-maternal generation, however, had a significant effect on the sex ratios in the sexual generation $(\mathrm{U}=$ $67.5, \mathrm{p}=0.003, \chi_{\text {approximation }}^{2}=9.040,1 \mathrm{df}, \mathrm{N}_{1}=12, \mathrm{~N}_{2}=6$ ).

Table 5.1: Sex ratio and density

\begin{tabular}{|c|c|c|c|}
\hline sex ratio & $\begin{array}{r}\text { experiment } 1 \\
\text { (1 or } 2 \text { mothers with } \\
\text { nymphs in box) }\end{array}$ & $\begin{array}{r}\text { experiment } 2 \\
\text { (1 or } 2 \text { mothers, nymphs } \\
\text { removed from box) }\end{array}$ & $\begin{array}{r}\text { experiment } 3 \\
\text { (1 or } 5 \text { grandmothers, } \\
\text { nymphs removed) }\end{array}$ \\
\hline low & $50 / 373=0.13(\mathrm{~N}=9)$ & $53 / 611=0.09(\mathrm{~N}=14)$ & $2 / 224=0.009(\mathrm{~N}=6)$ \\
\hline high & $88 / 607=0.15(\mathrm{~N}=9)$ & $117 / 1594=0.07(\mathrm{~N}=15)$ & $43 / 360=0.119(\mathrm{~N}=12)$ \\
\hline
\end{tabular}

The ratios are portions of male offspring (sons/sons+duaghters). The sample sizes are the number of replicates (standard boxes with one or two mothers respectively).

\section{Discussion}

The experimental design leads to pseudo-replication in the third experiment (variation of density at grand-maternal generation). This is not a problem for the first two experiments, because they have been designed to test the effect of density on the sexuparae. If the sexuparae were able to allocate their offspring sex ratio according to circumstances, they should do so independently of the fact that they were identical by descent. The third experiment, however, suffers from pseudo-replication. If, for example, density only affected the grandmothers of the sexual generation during an early developmental stage, this experiment tested the sex allocation of one against five grandmothers. The resulting offspring sex ratios produced by the sexuparae differed significantly, but this would need to be replicated at the level of the grand-maternal generation. Despite this flaw in experimental design, one conclusion is possible. Sexuparae are not able to allocate their offspring sex ratio from their fourth instar onwards. This disagrees with the assumption of Yamaguchi (1985) and supports the hypothesis of Kindlmann \& Dixon (1989).

The treatments within experiment one and two did not differ significantly, but the sex ratios between both experiments did. This suggests that the conditions experienced by the nymphs transferred into short day conditions (grandmothers) have not been identical. In particular, the second experiment resulted in a high frequency of sexuparae that gave birth to 
no male at all and the overall sex ratio was lower. It is therefore not unlikely that the density experienced by the grandmothers of experiment 2 was lower than the one experienced by the grandmothers in experiment 1.

If exclusively female producing sexuparae were separated from their male producing sisters and no male happened to find their daughters during migration, their reproductive success would be zero. It is therefore remarkable that sex allocation resulted in sexuparae that produced no male offspring at all. This might be an inevitable effect of selection for low portions of males working on the grandmothers rather than the sexuparous mothers of sexual aphids. The sexual females emerging from exclusively daughter producing sexuparae will depend on males of other sexuparae for fertilisation. Some 2 males might suffice to fertilise 222 sexual females in principle (cf. table 5.1). The vagaries of natural conditions, however, would split many sexuparae apart. Even if the sexuparae from one grandmother stay together and found a colony together, an accident killing the one male producing sexuparous female (or killing the grandmother before bearing any male producing sexuparae) would have sufficed to lead to a colony of sexual females with no male among them. Such a colony would entirely depend on external males finding them. This might be an explanation for the regular finding of sexual females dieing unfertilised in the field (own observations).

Comparing the overall sex ratios from experiment 3 with the ones expected from the formula by Hamilton (1967) reveals two things. Calculating the number of founding females $N$ from the portion of males $r$ yields approximately 1 for the case where the number of grandmothers has indeed been 1 . Of 224 sexual animals emerging from the single grandmother 2 were male. Inserting this portion of males $(r=0.009)$ into Hamilton's equation

$$
r=\frac{N-1}{2 N}
$$

yields a number of founding females close to $1(N=1.018)$. In the case of 5 grandmothers, 43 of 360 sexual animals were male $(r=0.119)$. This value delivers a number of founding females that is still quite close to $1(N=1.312)$. Inserting $N=5$ into Hamilton's equation, however, yields a high portion of males $(r=0.4)$.

Hamilton's model, however, is based on the assumption that founding females are assorted randomly as far as their relatedness is concerned. Assuming that an aphid cannot perceive its relatedness with a con-specific, a deviation of measured from expected sex ratios can serve as an estimate of the degree to which the aphid population deviates from panmixis. If the probability that five grandmothers of aphids stemmed from more than two clones was quite high, the sex ratio in their grandchildren should be quite close to the one predicted for 1 or 2 non-related founding females by Hamilton's equation. 
The second equation

$$
r=\frac{1-F}{2}
$$

can be used to calculate the difference between the degrees of kin competition in the sexual generation of $U$. cirsii and a panmictic population respectively. Five founding mothers from a panmictic population should produce sons in $40 \%$ of their offspring $(r=0.4)$. This relates to a comparatively low degree of kin competition $(F=0.2)$. Five grandmothers of $U$. cirsii produced a far lower proportion of males in the sexual generation $(r=0.119)$. This relates to a comparatively high degree of local mate competition $(F=0.762)$. The difference is 0.562 . If this was a measure for the deviation of the experimental population of $U$. cirsii from panmixis, it should be half way towards full sib mating and competition. It is not clear, however, how this measure will change in dependence to differing numbers of founding mothers (grandmothers in the case of aphids).

\section{Concluding remarks}

The experiments on density effects should be repeated carefully avoiding pseudo-replication. A more fine grained experimental design would also be favourable, because the above experiments only discriminate effects working on sexuparae from their fourth instar onwards from effects working on grandmothers plus sexuparae (mothers) up to their fourth instar. In order to conclude on population structure (kin competition), it would be necessary to compare sex ratios from replicates with many different numbers of founding grand(mothers). It would be particularly interesting to link such a study to patterns of differential sex allocation with varying maternal condition as found above. 


\section{Jumping genes, ancient asexual scandals, and the paradox of sex ${ }^{*}$}

\section{The twin-problem}

Sexual recombination accelerates the rate at which evolutionary change is possible (Fisher 1930, in a variorum edition from 1999; Muller 1932; Maynard Smith 1978), because two beneficial mutations at different loci that arose simultaneously in different individuals can both become established and fixed through sexual recombination. In asexual species, on the contrary, the two beneficial mutations would need to arise sequentially in individuals of the same lineage. Given identical mutation rates this would take much longer. Secondly, sex can reduce the load of deleterious mutations by the positive selection of recombinant individuals with less than the average number of deleterious mutations and negative selection against recombinants with more than the average number (Muller 1964; Maynard Smith 1978). These advantages, however, only accrue to individuals in the long-term (Maynard Smith 1984). They could also be conceived as advantages that accrue to groups in the short-term (Kondrashov 1993), but this requires a hierarchical conception that considers several levels of selection (see below, The distinction between replicators and interactors).

Genes for asexual reproduction could gain a two-fold immediate advantage over genes for sexual reproduction in an egg/sperm dimorphic (anisogamous) species without parental care, because males provide virtually nothing but genetic information to their offspring whereas females deliver all the resources. All else being equal, the genes of a parthenogenetic female will be twice as frequent in her progeny than the genes of a sexual female. Nevertheless, these theoretical expectations are not obeyed in nature. Despite the immediate cost of sexual reproduction, the majority of animal and plant species is sexual and anisogamous; and despite the long-term disadvantages of asexual reproduction, a few asexual taxa like bdelloid rotifers have grown evolutionarily ancient without any signs of imminent extinction. The latter have therefore been referred to as 'ancient asexual scandals' (Maynard Smith 1986; Judson \& Normark 1996).

Hence evolutionary biologists are dealing with a twin-problem: 1) What maintains sexual reproduction in the short-term, despite a two-fold immediate advantage to an asexual competitor? 2) What has kept a few ancient asexual taxa from extinction, despite the longterm disadvantages of genetic inflexibility and mutation accumulation? This essay attempts to provide an unified perspective on both problems from a jumping gene's eye view.

\footnotetext{
* submitted to Evolution
} 


\section{The distinction between replicators and interactors}

Dawkins (1976) has introduced the concepts of the evolutionary replicator and vehicle, where replicators are genes or memes and vehicles are a very diverse set of units. Hull (1980) has renamed Dawkins evolutionary vehicle into interactor, in order to stress their active role. While organisms are the most obvious units responding to the interactor concept, smaller parts as well as groups of organisms can also function as interactors is cases. Transposable elements, for example, are smaller parts of organisms that can be addressed as replicators which are their own interactors, because they can replicate at the expense of their host organism (Doolittle \& Sapienza 1980; Orgel \& Crick 1980; Hickey 1982; Bestor 1999; Woodruff et al. 1999). Although these terms might seem to be reifications, together they are useful for understanding evolution as a two step process, where the differential survival of interactors leads to the differential proliferation of replicators. Replicators in turn inherit information that can affect phenotypic traits of interactors differentially.

According to this scheme, evolutionary question can be aptly put into two categories: 1) Who interacts (using which strategies)? 2) Who benefits (which replicator increases)? Group selection, for example, would be about the differential survival of interactors that happen to consist of groups of organisms (e.g., Wilson 2001). Suppose a population structured into breeding groups that dissolve after a few generations and mix before new breeding groups are formed at random. Selfish freeloaders will have a reproductive advantage within groups of altruists, but groups with few altruists will have a large disadvantage (e.g., at defending a territory) in competition with other groups (e.g., Wilson \& Dougatkin 1997). This between-group advantage of genes for altruists might override the within-group advantage of genes for cheats. Hence, the benefit of group selection goes to replicators.

The paradox of sexual reproduction and the ancient asexual scandals demand an answer in terms of replicators, because they ask about the evolutionary benefit of sexual or asexual reproduction respectively. Nevertheless, the paradox of sex is commonly introduced by imagining an ominous parthenogenetic female that competes with sexual organisms and the scandal about bdelloids is that these organisms have not become feeble in the least.

\section{Asexual reproduction without long-term detriment}

Suppose an asexual organism containing only one operon that encoded all the proximate functions for development and reproduction of the organism and was also transposable in a genome that was constrained to a certain maximal size by resource limitation but nevertheless orders of magnitude larger than the operon. Suppose further that some epigenetic automatism 
(feedback) regulated genetic activity (transcription rate) according to the dose of functional operons in the genome. Starting with one operon, the genome would fill up with copies until as many operons became dysfunctional through mutations like point mutations, insertions, deletions, etc., as were newly established on average. While mutations would accumulate, however, not mutated 'backup' copies would still be around. If, for example, every fourth operon mutated during intra-genomic replication or reproduction of the organism, about three quarters of the genome would fill up with not mutated copies of the operon. A mathematical formulation of the transposition-selection balance has been worked out in a different context for 'parasitic' transposons (Charlesworth \& Langley 1989; Charlesworth et al. 1994).

Hence, asexual reproduction does not necessarily bear the long-term disadvantage of mutation accumulation. This long-term disadvantage has been accepted on the base of the assumption that genomes consisted almost exclusively of coding regions, had stable structures, and that sexual recombination was the only source of recombination. This idea, however, is long dated. Genomes are now known to contain enormous amounts of non-coding DNA (e.g., Brosius 1999; Dimitri \& Junakovic 1999; Makalowski 2000) and to have a continuously scrambled structure, because of asexual recombination within genomes through duplication and deletion, ectopic exchange, transposition , etc., (e.g., Shapiro 1999; Kidwell \& Lisch 1997, 2001). These insights even lead some authors to regard some genomes as fluids rather than solids (e.g., Palmer et al. 2000). The fixation of advantageous mutations should also become a quicker process, because multiple copies of genes can 'capture' more advantageous mutations than single copies. Advantageous mutations that arose in different copies might even be brought together into one copy through intra-genome recombination. The following evidence on some ancient asexual lineages shows that their genome structure is neither frozen nor are all their genes in mutational decay.

\section{Some evidence on ancient asexual scandals}

The Bdelloidea Hudson, a monophyletic class of rotifers with four families, 18 genera and some 360 described species, have existed for 35 to 40 million years and constitute the bestestablished case of ancient asexuality. Mark Welch \& Meselson (1998) have measured the genome sizes of one monogonont (sexual) and two bdelloid (asexual) rotifers. Both the bdelloids have larger genomes (2.2 and $1.0 \mathrm{pg}$ ) than the monogonont $(0.7 \mathrm{pg})$. Furthermore, the genomes of each of seven sexually reproducing rotifers have been found to contain either two nearly identical sequences or only a single sequence of the stress-inducible gene HSP82 for a so-called heat-shock protein, while the four bdelloid genomes examined contain two or 
more divergent copies of this gene in comparison (Mark Welch \& Meselson 2000). The asexual bdelloids also have more copies of other genes (Mark Welch \& Meselson 1998, 2000, 2001a); these copies are more divergent (Mark Welch \& Meselson 2000, 2001a, b) and contain more introns (Mark Welch \& Meselson 2000, 2001a) than those of the monogonont. Bdelloid rotifers do not seem to have a larger load of deleterious mutations, however, in spite of a similar mutation rate to that of monogonont rotifers (Mark Welch \& Meselson 2001b).

Another ancient asexual taxon is the Darwinulidae Brady \& Norman, a family of ostracod crustaceans with some 27 recent species and a remarkably good fossil record dating back 250 million years (Schön et al. 1998; Butlin et al. 1998). While single copy genes of sexual (monogonot) rotifers have additional copies in asexual (bdelloid) rotifers, research on dawinulids has concentrated on the so-called internal transcribed spacers (ITS) of an array of repetitive ribosomal DNA. ITS 1 and ITS 2 are two stretches of DNA separating the three nuclear genes coding for ribosomal RNA (18S, 5.8S and 28S). They are transcribed but then spliced out before the RNA is used to construct the ribosomes. The whole DNA arrangement (18S, ITS1, 5.8S, ITS2, 28S plus external spacers) is repeated in arrays of many copies. According to the 'Meselson hypothesis' (Mark Welch \& Meselson 2000), the copies of ITS should have diverged strongly because of independent mutation accumulation in asexual lineages. Nevertheless, the sequences of ITS have diverged far less than has been expected (Schön et al. 1998). Further evidence now suggests that gene conversion and recombination within and between tandemly repeated arrays of ribosomal DNA of a genome works against mutation accumulation (Butlin 2000; Gandolfi et al. 2001). It would be interesting to know whether additional copies of 'regular' genes that are not part of repetitive arrays also occur in darwinulids and whether ITS of bdelloids are also not accumulating mutations.

Palmer et al. (2000) have described the mitochondrial DNA (mtDNA) of angiosperm plants as having "experienced remarkably high rates of gene loss and concomitant transfer to the nucleus and of intron acquisition by horizontal transfer". The remaining mtDNA is characterised by frequent duplications, deletions and the "capture of sequences from the chloroplast and nucleus". Inversions and recombination between small and large repeats are "frequent enough to scramble gene order almost completely, even among relatively closely (sic) members of the same genus" rendering the mitochondrial genome a "nearly equimolar mixture of recombinational isomers" (Palmer et al. 2000). That plant mtDNA evolves rapidly in structure but slowly in sequence has been known for a long time (Palmer et al. 2000). A particularly striking point is that, in many plants, the relative rate of gene transposition for ribosomal proteins actually exceeds the rate of nucleotide substitution at individual silent sites 
(Adams et al. 2000). Although exchange with the nuclear and chloroplast genomes means that these mitochondria are not entirely clonal, this evidence fits well to the idea that gene jumping can compensate the disadvantages of long-term asexual reproduction.

The clonality (asexuality) of animal and particularly human mitochondria is the subject of an ongoing debate (proceeding along Eyre-Walker et al. 1999a; Hagelberg et al. 1999; Macaulay et al. 1999; Eyre-Walker et al. 1999b; Awadalla et al. 1999; Kivisdil \& Villems 2000, with following discussion at www.sciencemag.org/cgi/content/full/288/5473/ 1931a; Eyre-Walker 2000). Eyre-Walker and colleagues seem to favour so-called paternal leakage as a mechanism of explaining the high degree of homoplasy (parallel point mutations) and lack of linkage disequilibrium (Eyre-Walker et al. 1999a; Awadalla et al. 1999). A few mitochondria of the sperm cell penetrate the zygote but are then degraded. The paternal leakage hypothesis suggests that some pieces of mitochondrial DNA from the sperm can nevertheless be integrated into the mitochondria of the zygote. Other forms of gene jumping, however, are also being considered (e.g., Eyre-Walker 2000).

\section{Integrating the new perspective}

An alternative explanation for the continued existence of an asexual population is via multiple origins of new asexual clones from a sexual species. In this model, an asexual population would represent a heterogeneous compilation of asexual clones that are continuously spinning off from a sexual species and that are balanced by the high extinction rate of these clones (e.g., Hamilton et al. 1981; Howard \& Lively 1994; Butlin et al. 1998; Schön et al. 2000). Asexual clones of aphids such as Rhopalosiphum padi (L.) retain the ability to produce a small portion of males that can mate with sexual females from the same species. This results in new clones, which in spite of being produced sexually are asexual in turn (Delmotte et al. 2001). Occasional long-term survivors escaping such a dynamic equilibrium between the frequent establishment and extinction of asexual clones might have given rise to a few wellseparated and ancient taxa of asexual organisms, such as the bdelloids or darwinulids.

The most suitable groups for addressing questions relating to this middle-term evolution of asexual lineages are taxa such as Tramini Herrich-Schaeffer (Hemiptera, Aphidoidea), Cypris O.F. Müller (Crustacea, Ostracoda), or parthenogenetic populations of the genus Artemia Leach (Crustacea, Anostraca). These groups combine a long history of widespread asexual reproduction with a generally reduced but miscellaneous degree of sexual reproduction (MacDonald \& Browne 1987; Browne 1992; Browne \& Hoopes 1990; Butlin et al. 1998; Schön et al. 2000; Blackman et al. 2000, 2001). The karyotypes of these species are 
structurally highly heterogeneous and sometimes aneuploid or polyploid. The genomes are not organised into homologous sets of genes and chromosomes, because of various multiplications and rearrangements (e.g., Abatzopoulos et al. 1986; Turgeon \& Hebert 1994, 1995; Normark 1999; Blackman et al. 2000). The chromosomes are sometimes connected by fine threads indicating ectopic exchange (e.g., Abatzopoulos et al. 1986). Blackman et al. (2000) have also found a multiplication of the number of ribosomal DNA arrays in Tramini. The study of specific DNA sequences, however, did not provide consistent evidence for mutation accumulation. As in ancient asexual taxa, the genome structure is not conserved, but some genetic sequences are (Normark 1999), while others diverged (Schön et al. 2000).

Long-term survival of asexual lineages suggests that they should have some means of recombination other than sexual recombination during meiosis and syngamy. Would a solution of the problem of long-term asexual reproduction, however, not exacerbate the paradox of sex? After all, a parthenogenetic female should immediately gain twice the reproductive success than her sexual competitors.

\section{Sexual reproduction without a two-fold immediate cost}

Is it possible to reformulate and unify hypotheses about the maintenance of sex in terms of jumping genes - now between genomes? Sexual recombination may be seen as a way of regular germ-line replicators (not transposable elements) to jump out of an unfavourable genetic background (cf., Otto \& Feldman 1997). An individual germ-line replicator would get rid of a deleterious mutation at another locus in every second sexually produced gamete on average, which is only half as bad as being entirely stuck with it in an asexual lineage.

Another major hypothesis for the maintenance of sex regards sexual recombination as adaptive in an evolutionary arms race against parasites (e.g., Hamilton 1980; Hamilton et al. 1990). If a parasite 'breaks' a certain defensive trait of its host (e.g., a toxic plant alkaloid) no single allele will become dysfunctional as through a deleterious mutation. Nevertheless, it is usually possible to restore defence through substituting alleles in one of the loci involved in the defensive function (Flor 1971). Through sexual recombination, individual replicators can jump out of a genetic background that has become susceptible to a parasite, in the same way as they can jump away from a deleterious mutation in that genetic background. It is not unlikely that other hypotheses on the maintenance of sex can also be reformulated according to a jumping gene's perspective, and this might yield a more unified picture. In conclusion, the jumping gene's eye view has the potential for a unified perspective on two of the most intricate problems of evolutionary biology, the paradox of sex and ancient asexual scandals. 


\section{General Conclusions}

\section{Interactors, replicators, and evolutionary theory}

The distinction between evolutionary replicators (Dawkins 1976) and interactors (Hull 1980) has been around ever since August Weissmann proclaimed the separation of germ-plasm and soma in 1883 (e.g., as the discrimination between genotype and phenotype). Although these terms might seem to be reifications, they are useful for understanding evolution as a dual process: The differential survival of interactors leads to the differential proliferation of replicators. A missing link in this scheme is how heritable information from replicators is translated into new phenes (Arthur 2002). This translation of the genetic information, however, is not yet included into conceptions of natural selection but is regarded as belonging to developmental biology. The neologism translator has not yet been used, but the recent upsurge of 'evo-devo' indicates a new interest into the role of development in evolution. If evo-devo was not just filling in the gory details of development but a genuine synthesis in progress, evolution might soon be thought of as a triple process: (1.) interactor survival, (2.) replicator proliferation, and (3.) translator expression. While development is not relevance here, the interactor-replicator distinction allows an integration of the above results.

Evolutionary interactors are very diverse, indeed, and it seems to be uncontroversial that a hierarchy of interactors exists. Sperm and egg cells, and the zygotes and organisms emerging from their fusion, are among the most obvious interactors. Life cycles are such vehicles on a larger temporal scale and breeding populations with their various features (e.g., sex ratio and kin structure) are vehicles on a larger spatial scale. Natural selection leads to differential survival of these units, which in turn leads to differential proliferation of their germ-line replicators.

Replicators of two fundamentally different kinds are recognised today. Germ-line replicators are genetic (e.g., genes, transposable elements, parasitic DNA), whereas cultural replicators are memetic (e.g., ideas, traditions, fashions, tunes) and copied by imitation (Blackmore 1999). According to Blackmore (1999), many peculiarities of human nature can be explained as benefiting memes. For most organisms, however, memes are irrelevant, because these organisms do not imitate each other and have no culture.

Even group selection is no longer a heresy against orthodox evolutionary theory in this modern guise (e.g., Wilson 2001). Suppose a population is structured into breeding groups that dissolve after a few generations and mix before new breeding groups are formed. In this 
situation, between-group selection needs to be distinguished from within-group selection. Suppose further that a group of co-operating altruists has a higher capacity to gain and defend resources (e.g., territory). Within each group of altruists, selfish freeloaders will have a higher average fitness but all individuals of a group of altruists will do much better than those in a group of egoists. This overall benefit can statistically prevail over the within-advantage of cheats (e.g., Wilson \& Dougatkin 1997, Wilson 2001). Thus, the fitness of the cheats is frequency-dependent. They only do better in groups that are dominated by co-operating altruists but do far worse in groups that are dominated by their own kind. Many genes for selfish behaviour will be negatively selected, when their frequency has become too high either through steady increase within a group or through the stochastic raffle preceding the formation of new breeding groups.

\section{Interactor selection: Which strategy survives?}

Strategies of life history, sex allocation, mating behaviour and sperm competition can be seen as vehicles that are under natural selection. These various interactions need to be integrated, in order to lead to the successful proliferation of germ-line replicators. How are these evolutionary vehicles integrated?

The life history of a species influences its population dynamics throughout the year and sets the degree of kin competition among males or females. This selects for a sex allocation strategy adapted to the life history frame. The operative sex ratio resulting from this sex allocation in turn sets the stage on which each individual has to play out its life as successful as possible. This requires an adaptive mating behaviour of individuals. For example, the guarding of females should be adaptive at high degrees of competition from other males, but a maladaptive waste of time at low degrees of competition in strongly female-biased breeding populations. Mating behaviour will also be influenced by the nature of sperm competition.

The simplest model that relates mating behaviour to sperm competition would assume that mate guarding after copulation indicates the last male's sperm precedence in fertilising eggs (e.g., dung flies, cf. Parker 1970a), whereas pre-copula mate guarding indicates the first male's sperm precedence (e.g., snapping shrimp, cf. Mathews 2002). On the other hand, postcopula guarding is not cogently associated with a strong precedence of the last male's sperm in fertilising a female's eggs. Post-copula guarding will be adaptive whenever the 'guarding' strategy gains a differential reproductive advantage over the 'non-guarding' strategy, even if a later male could not gain any sperm precedence and its P2-value would fall short of 0.5 (e.g., 
Dickison 1995, Simmons \& Siva-Jothy 1998). This differential advantage for the guarding strategy should, of course, wax and wane with the portion of males or sex ratio.

Life history strategies need to be adapted to a dynamically changing environment. Life history influences population structure including competition structure. Different sex allocation strategies will be adaptive under different risks of kin competition. The operative sex ratio resulting from adaptive sex allocation will in turn affect both the likelihood of sperm competition and mate competition thus setting the stage for adaptive mating behaviour.

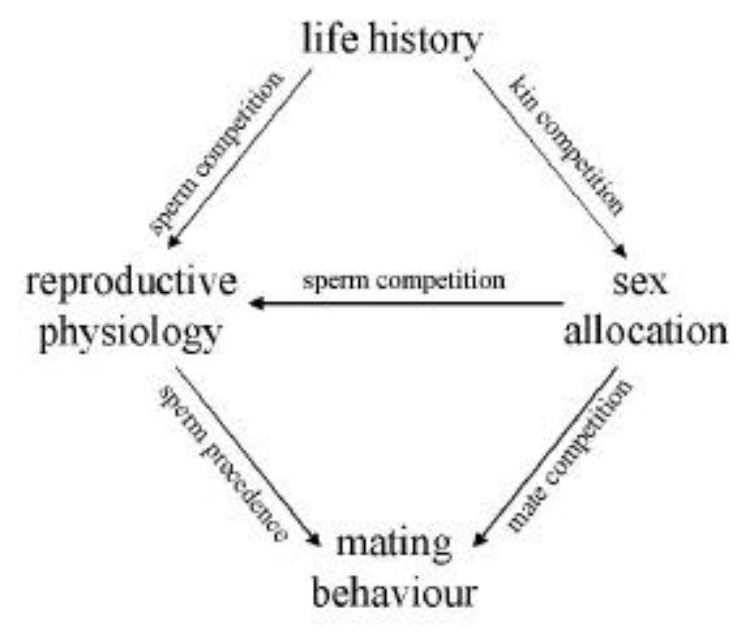

This scheme of interactor integration can be illustrated at the example of some above studied aphids. The most obvious difference in the life histories of the birch aphid E. betulae and the hawksbeard aphid $U$. cichorii, for example, lies in the wing polymorphism and mobility of the parthenogenetic morphs (cf. chapter 3). In E. betulae, all parthenogenetic individuals are winged and apt flyers. Their ecological niche is closer to that of leafhoppers (Psyllidae) than to that of the sedentary and colonial aphid U. cichorii. Therefore, clones of $E$. betulae will be better mixed than those of $U$. cichorii. On a scale ranging from random to sib competition, competition among male E. betulae should be closer to random, whereas competition among male $U$. cichorii should be closer to kin. This difference in competition among related males selects for different sex ratios. The resulting operative sex ratio will in turn increase sperm competition and set the stage for individual mating behaviour. The higher proportion of males and the more scattered distribution of females among sexual E. betulae select for mate guarding. With the low proportion of males and the clumped distribution of females in sexual $U$. cichorii, however, mate guarding would be a maladaptive waste of time. 


\section{Replicator selection: Who benefits?}

From an organism's eye view, a parthenogenetic female should gain a two-fold immediate reproductive advantage over sexual females. Nevertheless, the majority of animal and plant species reproduces sexually. This so-called paradox of sex can be rephrased as a twofold question: Which strategy survives and which replicator proliferates? Put this way, the question about benefits obviously demands an answer in terms of replicators not interactors. Therefore, asking about the benefit of recombination for sexual organisms in the face of a parthenogenetic female as the competitor seems to be misleading, because it compounds levels of selection. Sexual and asexual reproduction are the survival strategies, but the evolutionary benefit should be sought in terms of differential replicator selection. 


\section{Summary}

Second copulas of Uroleucon cirsii (L.) are shorter on average than first copulas both for individual males and females. This suggests that male aphids are limited by sperm, on the one hand, and that the capacity of females to store sperm is neither unlimited. The latter could be the case if sperm from previous copulas was not displaced. In agreement with this, aphid sperm seems to be transmitted in co-operating bundles with the sperm-heads sticking together and the flagella beating synchronously.

A male should leave a female when the gain rate in fertilised eggs has dropped to the average gain rate for the habitat. This marginal value theorem was applied to field colonies of the pine needle aphid Schizolachnus obscurus Börner with one and two males respectively. While the search time was higher in colonies with two males, the copula duration was similar. The difference in copula duration predicted from the marginal value model, however, was very small suggesting that it could not be detected in the 'noisy' field data. Nevertheless, the average post-copula lasts twice as long in colonies with two males as in colonies with one male. This was due to a higher frequency of prolonged post-copula association and a lower frequency of simply dismounting in colonies with two males suggesting that male $S$. obscurus are more likely to guard females in the presence of competitors.

Aphid species with males that guard each female after copulation can be expected to have less female-biased sex ratios than those with males that only guard infrequently or not at all. This hypothesis has been found to be true for the mate-guarding Euceraphis betulae Koch and the non-guarding Uroleucon cichorii (Koch). This suggests that a transition from nonguarding towards guarding aphids should take place between sex ratios of 13 and 2.5 females per male. If this was true, species with more female-biased sex ratios should not guard, whereas species with less female-biased sex ratios should guard or copulate for longer than is necessary for fertilisation.

Asymmetries in kin competition among males or females select for biased sex ratios. Within this overall sex ratio, individuals should allocate their resources differentially to daughters and sons according to their differing conditions and returns in fitness for each offspring sex. These differential sex ratios have been analysed for two aphid species suggesting that kin competition among males prevails in Uroleucon cirsii (L.), but that kin competition among females occurs in Rhopalosiphum padi (L.). This is not implausible, because the life cycle of $R$. padi effectively prevents kin competition among males through 
their migration but not resource competition among related females.

Population density experienced by the mothers of the sexual generation of $U$. cirsii as adults or nymphs did not affect the sex ratio. Differences experienced by the grandmothers, however, did affect the sex ratio. This confirms the hypotheses that sex allocation takes place in the parthenogenetic grandmothers of the sexual generation, because an aphid begins to develop at a time when its parthenogenetic mother is itself still an embryo (telescoping of generations). Nevertheless, a methodological pitfall leading to pseudo-replication still needs to be tackled.

Sexual reproduction accelerates the rate of evolutionary change and purges the gene pool of deleterious mutations by occasionally recombining them into non-viable offspring. Despite these long-term advantages of sex, genes causing ameiotic parthenogenesis should gain a two-fold representation in the next generation. This raises two questions: 1) Why has sexual reproduction been maintained in the majority of animal and plant species, despite a two-fold immediate advantage to genes in an asexual competitor? 2) What has kept a few ancient asexual taxa, such as the bdelloid rotifers from extinction, despite the long-term disadvantages of evolutionary inflexibility and mutation accumulation? Through recombination, any germ-line replicator will end up together with a particular mutation at another position in the genome in only half of the gametes produced. That is twice as good as in asexual lineages. At the same time, transposition of functional operons can in principle avoid the detriment of mutation accumulation. Such a 'fluid' and modular genome can be seen as a dynamic state between the establishment of new functional copies of genes and their destruction through mutation. Thus, the jumping gene's perspective may deliver one answer to two important questions of current evolutionary theory. 


\section{Zusammenfassung}

Die durchschnittliche Dauer der zweiten Kopulation von Uroleucon cirsii (L.) ist sowohl für Männchen als auch für Weibchen kürzer als die der ersten. Dies legt die Vermutung nahe, dass die männlichen Blattläusen zur Verfügung stehende Menge Sperma limitiert ist. Des weiteren wird Ejakulat von vorherigen Paarungen anscheinend nicht verdrängt, so dass die Kapazität der Weibchen, weiteres Sperma zu speichern, ebenfalls begrenzt ist. Diese Vermutung bestätigend wird das Sperma von $U$. cirsii in kooperativen Bündeln übertragen, bei denen die Seprmienköpfe zusammenhängen und die Flagellen synchron schlagen.

Männchen einer polygamen Art sollten ein Weibchen verlassen, wenn ihre Zuwachsrate an befruchteten Eiern auf das durchschnittliche Niveau für das Habitat gefallen ist. Dieser Grenzwertsatz wurde auf Freilandkolonien von Schizolachnus obscurus Börner mit einem beziehungsweise zwei Männchen angewandt. Während die durchschnittliche Suche nach Weibchen in Kolonien mit zwei Männchen länger dauerte als in Kolonien mit einem Männchen, war die Kopulationsdauer etwa gleich lang. Der durch das Grenzwert-Modell vorhergesagte Unterschied in der Kopulationsdauer war allerdings zu gering, um ihn in den ,verrauschten“ Freilanddaten zu entdecken. Die durchschnittliche Post-Kopula dauerte in Kolonien mit zwei Männchen allerdings doppelt solange wie in Kolonien mit einem Männchen. Dies lag an einer höheren Frequenz verlängerter Post-Kopula-Assoziationen und einer niedrigeren Frequenz einfachen ,Herabsteigens‘. Anscheinend bewachen Männchen von S. obscurus Weibchen eher, wenn Konkurrenten anwesend sind.

Blattlausarten, deren Männchen jedes Weibchen nach der Kopulation bewachen, sollten im Durchschnitt weniger Weibchen pro Männchen aufweisen als solche Arten, deren Männchen sie nur manchmal oder nie bewachen. Dies konnte für die bewachende Art Eueraphis betulae Koch und die nicht bewachende Art Uroleucon cichorii (Koch) bestätigt werden. Der Übergang von bewachenden zu nicht bewachenden Blattlausarten scheint zwischen einem Verhältnis der Geschlechter von 2,5 und 13 Weibchen pro Männchen zu liegen. Wenn dies zuträfe, sollte Bewachung in Arten mit weniger als 2,5 Weibchen pro Männchen zu erwarten sein, aber nicht in Arten mit mehr als 13 Weibchen pro Männchen.

Bei Asymmetrien in der Konkurrenz zwischen verwandten Individuen desselben Geschlechts werden unausgeglichene Verhältnisse in der Gesamtzahl von Männchen und Weibchen vorteilhaft. Innerhalb dieses Gesamtverhältnisses der Geschlechter sollten die Individuen, je nach ihrer Konstitution und dem für sie zu erwartenden Reproduktionserfolg 
durch die Nachkommen jedes Geschlechts, unterschiedlich viel Ressourcen in Töchter und Söhne investieren. Dies wurde an zwei Blattlausarten überprüft. Die Ergebnisse legen nahe, dass bei Uroleucon cirsii (L.) die Konkurrenz unter verwandten Männchen überwiegt, während bei Rhopalosiphum padi (L.) verwandte Weibchen in stärkerer Konkurrenz zueinander stehen. Dies ist auch plausibel, weil der Lebenszyklus von $R$. padi die Konkurrenz zwischen verwandten Männchen durch deren Migration verhindert, aber nicht die Konkurrenz zwischen verwandten Weibchen um Ressourcen.

Während sich die Mütter der sexuellen Generation von $U$. cirsii von Nymphen zu Adulten entwickeln, haben Unterschiede in der Populationsdichte keinen Effekt mehr auf das Geschlechter-Verhältnis ihres Nachwuchses. Ein Effekt der Populationsdichte während der Entwicklung der Großmütter der sexuellen Generation ist jedoch vorhanden. Dies stimmt mit der Annahme überein, dass das Geschlecht der sexuellen Tiere bereits in ihren Großmüttern festgelegt wird, weil ihre Entwicklung bereits beginnt, während seine Mütter noch Embryonen sind (teleskopartig zusammen geschobene Generationen). Ein methodisches Problem, welches zu Pseudo-Replikation führt, müßte allerdings noch ausgeräumt werden.

Sexuelle Fortpflanzung beschleunigt die Evolutionsrate einer Art, weil vorteilhafte Mutationen nicht nacheinander in derselben Fortpflanzungslinie auftreten müssen. Außerdem befreit sie den Genpool von schädlichen Mutationen, indem manchmal mehrere Mutationen miteinander rekombiniert werden und zusammen aussterben. Trotzdem sollten Mutationen für ameiotische Parthenogenese den kurzfristigen Reproduktionserfolg verdoppeln, weil sie in jedem Gameten vertreten sein werden. Dies wirft zwei Fragen auf. 1) Warum sind die meisten Tiere und Pflanzen sexuell, obwohl asexuelle Konkurrenten kurzfristig einen doppelt so hohen Reproduktionserfolg haben sollten? 2) Warum haben wenige asexuelle Taxa (z.B. Bdelloidea) trotz der erwarteten langfristigen Nachteile asexueller Fortpflanzung lange Zeiträume der Evolution überdauert? Durch sexuelle Rekombination landet ein KeimbahnReplikator nur in der Hälfte aller Gameten mit einem bestimmten mutierten Gen zusammen. Das ist doppelt so gut wie in asexuellen Fortpflanzungslinien. So betrachtet ist Rekombination das Herausspringen eines Replikators aus seinem genetischen Hintergrund. Auf der anderen Seite kann die Transposition funktionaler Operons innerhalb eines Genoms im Prinzip auch die Nachteile asexueller Fortpflanzung kompensieren. Ein solches ,flüssiges“ und modulares Genom kann als Fliessgleichgewicht zwischen der Etablierung neuer funktioneller Kopien von Genen und der Zerstörung ihrer Funktion durch Mutation angesehen werden. 


\section{References}

Abatzopoulos T.J., Kastritsis C.D. \& Triantaphyllidis C.D. 1986: A study of karyotypes and heterochromatic associations in Artemia, with special reference to two N. Greek populations. Genetica 71, 3-10

Adams K.L., Daley D.O., Yin-Long Q., Whelan J. \& Palmer J.D. 2000: Repeated, recent and diverse transfer of a mitochondrial gene to the nucleus in flowering plants. Nature 408, 354-357

Arthur W. 2002: The emerging conceptual framework of evolutionary developmental biology. Nature 415, 757-764

Awadalla P., Eyre-Walker A. \& Maynard-Smith J. 1999: Linkage disequilibrium and recombination in hominid mitochondrial DNA. Science 286, 2524-2525

Bernstein H. 1977: Germ line recombination may be primarily a manifestation of DNA repair processes. J. Theor. Biol. 69, 371-380

Bernstein H., Byerly H.C., Hopf A.C. \& Michod R.E. 1985: Genetic damage, mutation, and the evolution of sex. Science 229, 1277-1281

Bestor T.H. 1999: Sex brings transposons and genomes into conflict. Genetica 107, 289-295

Birkhead T.R. \& Parker G.A. 1997: Sperm competition and mating systems. In Krebs J.R. \& Davies N.B. (eds): Behavioural Ecology: an evolutionary approach, fourth edition. Blackwell Science, Oxford, pp. 121-145

Blackman R.L. 1987: Reproduction, cytogenetics and development. In Minks A.K. \& Harrewijn P. (eds): Aphids, vol. 2a. Elsevier, Amsterdam, pp. 163-195

Blackman R.L., Spence J.M. \& Normark B.B. 2000: High diversity of structurally heterozygous karyotypes and rDNA arrays in parthenogenetic aphids of the genus Trama (Aphididae: Lachnidae). Heredity 84, 254-260

Blackman R.L., Boise E. de \& Czylok A. 2001: Occurrence of sexual morphs in Trama troglodytes von Heyden, 1837 (Hemiptera, Aphididae). J. Nat. Hist. 35, 779-785

Blackmore, S. 1999: The meme machine. Oxford Univ. Press

Bonnet C. 1779: Oeuvres d'Histoire Naturelle et de Philosophie, vol. 1. Fauche, Neuchatel

Brosius J. 1999: Genomes were forged by massive bombardments with retroelements and retrosequences. Genetica 107, 209-238

Browne R.A. 1992: Population genetics and ecology of Artemia. Trends Ecol. Evol. 7, 232237. 
Browne R.A. \& Hoopes C.W. 1990: Genotype diversity and selection in asexual brine shrimp (Artemia). Evolution 44, 1035-1051

Buck J.B. 1953: Physical properties and chemical composition of insect blood. In Roeder K.D. (ed): Insect physiology. John Wiley \& Sons, New York, pp. 147-190

Buckton, G.B. 1876: Monograph of the British Aphides, vol. 1. Ray Society, London

Butlin R., Schön I. \& Martens K. 1998: Asexual reproduction in nonmarine ostracods. Heredity 81, 473-480.

Butlin R.K. 2000: Virgin rotifers. Trends Ecol. Evol. 15, 389-390

Charlesworth B. \& Langley C.H. 1989: The population genetics of Drosophila transposable elements. Annu. Rev. Genet. 23, 251-287

Charlesworth B., Sniegowski P. \& Stephan W. 1994: The evolutionary dynamics of repetitive DNA in eukaryotes. Nature 371, 215-220

Charnov E.L. 1976: Optimal foraging, the marginal value theorem. Theor. Popul. Biol. 9, $129-136$

Charnov E.L. 1982: Sex Allocation. Princeton Univ. Press, Princeton

Charnov E.L. \& Parker G.A. 1995: Dimensionless invariants from foraging theory's marginal value theorem. Proc. Natl. Acad. Sci. USA 92, 1446-1450

Dagg, J.L. 1999: Plant-induced change in the life-cycle of the pine aphid Schizolachnus pineti (F.). Ecol. Entomol. 24: 484-485 [http://www.GWDG.DE/ instphyt/vidal/welcomed.html]

Dagg J. \& Scheurer S. 1998: Observations on some patterns of the males' sexual behaviour of certain aphid species. In Nieto Nafría J.M. \& Dixon A.F.G. (eds): Aphids in Natural and Managed Ecosystems. Univ. León Publicaciones, León (Spain), pp. 167-171 [http://www.GWDG.DE/ instphyt/vidal/welcome-d.html]

Dawkins R. 1976: The selfish gene. Oxford Univ. Press, Oxford

Debout G., Fauvergue X. \& Fleury F. 2002: The effect of foundress number on ratio under partial local mate competition. Ecol. Entomol. 27, 242-246

Delmotte F., Leterme N., Bonhomme J., Rispe C. \& Simon J.-C. 2001: Multiple routes to asexuality in an aphid species. Proc R Soc Lond B 268, 2291-2299

Dickison J.L. 1995: Trade-offs between post-copulatory riding and mate location in the blue milkweed beetle. Behav. Ecol. 6, 280-286

Dimitri P. \& Junakovic N. 1999: Revising the selfish DNA hypothesis. Trends Genet. 15, $123-124$

Dixon A.F.G. 1998: Aphid ecology. Chapman \& Hall, London 
Dixon A.F.G. \& Glen D.M. 1971: Morph determination in the bird cherry-oat aphid, Rhopalosiphum padi L. Ann. Appl. Biol. 68, 11-21

Dixon A.F.G., Croghan P.C. \& Gowing R.P. 1990: The mechanism by which aphids adhere to smooth surfaces. J. Exp. Biol. 152, 243-253

Doherty H.M. \& Hales D. 2002: Mating success and mating behaviour of the aphid, Myzus persicae (Hemiptera: Ahididae). Europ. J. Entomol. 99, 23-27

Doolittle W.F. \& Sapienza C. 1980: Selfish genes, the phenotype paradigm and genome evolution. Nature 284, 601-603

Eberhard W.G. 1998: Female roles in sperm competition. In Birkhead T.R. \& Møller A.P. (eds) Sperm competition and sexual selection. Academic Press, San Diego, pp. 91-116

Eyre-Walker A. 2000: Do mitochondria recombine in humans. Phil. Trans. R. Soc. Lond. B 355, 1573-1580

Eyre-Walker A., Smith N.H. \& Maynard Smith J. 1999a: How clonal are human mitochondria? Proc. R. Soc. Lond. B 266, 477-483

Eyre-Walker A, Smith N.H. \& Maynard Smith J. 1999b: Reply to Macaulay et al: mtDNA recombination-reasons to panic. Proc. R. Soc. Lond. B 266, 2041-2042

Fisher R.A. 1930: The Genetic Theory of Natural Selection. In Bennett H. (ed) A complete variorum edition, 1999. Oxford Univ. Press, New York, pp. 1-268

Flor H.H. 1971: Current status of the gene-for-gene hypothesis. Ann. Rev. Phytopathol. 9, 275-296

Foster W.A. \& Benton T.G. 1992: Sex ratio, local mate competition and mating behaviour in the aphid Pemphigus spyrothecae. Behav. Ecol. Sociobiol. 30, 297-307

Frank S.A. 1986: Hierarchical selection theory and sex ratios. Theor. Popul. Biol. 29, 312-342

Galli E. 1998: Mating behaviour in Tetraneura nigriabdominalis Sasaki (=akinire Sasaki) (Hemiptera, Pemphiginae). Invert. Reprod. Develop. 34, 173-176

Gandolfi A., Bonilauri P., Rossi V. \& Menozzi P. 2001: Intraindividual and intraspecies variability of ITS1 sequences in the ancient asexual Darwinula stevensoni (Crustacea: Ostracoda). Heredity 87, 449-455

Geer C. de 1755: Observations sur les Éphéméres, sur les Pucerons, et sur des Galles Résineuses. Mémoires Math. Phys., prés. l'Académie R. Sci. Paris 2, 461-476

Goeze J.A.E. 1774: Herrn Karl Bonnets wie auch einiger andern beruehmten Naturforscher auserlesene Abhandlungen aus der Insektologie, aus dem Franzoesischen uebersetzt und mit einigen Zusaetzen herausgegeben von Joh. August Ephr. Goeze. Bey J.J. Gebauers Witwe und Joh. Jacob Gebauer, Halle 
Hagelberg E., Goldman N., Lió P., Whelan S., Schiefenhövel W., Clegg J.B. \& Bowden D.K. 1999: Evidence for mitochondrial DNA recombination in a human population of island Melanesia. Proc. R. Soc. Lond. B 266, 485-492

Hales D.F., Wellings P.W., Parkes R.A. 1989: Investment in gynoparae and males by Myzus persicae (Sulzer). Funct. Ecol. 3, 727-734

Hamilton W.D. 1967: Extraordinary sex ratios. Science 156, 477-488

Hamilton W.D. 1980: Sex versus non-sex versus parasites. Oikos 35: 282-290

Hamilton W.D., Henderson P.A. \& Moran N.A. 1981: Fluctuation of environment and coevolved antagonist polymorphism as factors in the maintenance of sex. In Hamilton W.D. 2001: Narrow roads of gene land, vol. 2. Oxford Univ. Press, pp. 25-50

Hamilton W.D., Axelrod R. \& Tanese R. 1990: Sexual reproduction as an adaptation to resist parasites. Proc. Natl. Acad. Sci. USA 87, 3566-3573

Hardy I.C.W. 1994: Sex ratio and mating structure in the parasitoid Hymenoptera. Oikos 69, $3-20$

Hayashi F. 1996: Insemination through an externally attached spermatophore: bundled sperm and post-copulatory mate guarding by male fishflies (Megaloptera: Corydalidae). J. Insect Physiol. 42, 859-866

Hayashi F. 1998: Sperm co-operation in the Fishfly, Parachauliodes japonicus. Funct. Ecol. 12, 347-350

Hickey D.A. 1982: Selfish DNA: a sexually transmitted nuclear parasite. Genetics 101, 519531

Howard R.S. \& Lively C.M. 1994: Parasitism, mutation accumulation and the maintenance of sex. Nature 367, 554-557

Hull, D.L. 1980: Individuality and selection. Ann. Rev. Ecol. Syst. 11, 311-332

Judson O.P. \& Normark B.B. 1996: Ancient asexual scandals. Trends Ecol. Evol. 11: 41-46

Kidwell M.G. \& Lisch D.R. 1997: Transposable elements as sources of variation in animals and plants. Proc. Natl. Acad. Sci. USA 94, 7704-7711

Kidwell M.G. \& Lisch D.R. 2001: Transposable elements, parasitic DNA, and genome evolution. Evolution 55, 1-24

Kindlmann P. \& Dixon A.F.G. 1998: Role of population density in determining the sex ratios of species that show local mate competition, with aphids as a model group. Funct. Ecol. 3, 311-314

Kivisild T. \& Villems R. 2000: Questioning evidence for recombination in human mitochondrial DNA. Science 290, 1931a 
Kondrashov S.A. 1982: Selection against harmful mutations in large sexual and asexual populations. Genet. Res., Camb. 40, 325-332

Kondrashov S.A 1993: Classification of hypotheses on the advantage of amphimixis. J. Heredity 84: 372-387

Kozlowski M.W. 1991: Mating behaviour and high level polygamy in the aphids, Periphillus acericola and Drepanosiphum platanoidis (Homoptera Drepanosiphidae). Ethol. Ecol. Evol. 3, 285-294

Küppers G. \& Zimmremann U. 1983: Cell fusion by spark discharge and its relevance for evolutionary processes. FEBS Letters 164, 323-329

Macaulay V., Richards M. \& Sykes B. 1999: mtDNA recombination-no need to panic. Proc. R. Soc. Lond. B 266, 2037-2039

MacDonald G.H. \& Browne R.A. 1987: Inheritance and reproductive role of rare males in a parthenogenetic population of the brine shrimp, Artemia parthenogenetica. Genetica 75, $47-53$

Makalowski W. 2000: Genomic scrap yards: how genomes utilize all that junk. Gene 259, 6167

Margulis L. \& Sagan D. 1986: Origins of sex. Yale University Press, New Haven

Mark Welch D.B. \& Meselson M. 1998: Measurement of the genome size of the monogonont rotifer Brachionus plicatilis and of the bdelloid rotifers Philodina roseola and Habrotrocha constricta. Hydrobiologia 387/388, 395-402

Mark Welch D. \& Meselson M. 2000: Evidence for the evolution of bdelloid rotifers without sexual reproduction or genetic exchange. Science 288, 1211-1215

Mark Welch D.B. \& Meselson M. 2001a: A survey of introns in three genes of rotifers. Hydrobiologia 446/447, 333-336

Mark Welch D.B. \& Meselson M.S. 2001b: Rates of nucleotide substitution in sexual and anciently asexual rotifers. Proc. Natl. Acad. Sci. USA 98, 6720-6724

Mathews L.M. 2002: Tests of the mate-guarding hypothesis for social monogamy: does population density, sex ratio, or female synchrony affect behavior of male snapping shrimp. Behav. Ecol. Sociobiol. 51, 426-432

May R.M. \& Seger J. 1985: Sex ratios in wasps and aphids. Nature 318, 408-409

Maynard Smith J. 1978: The Evolution of Sex. Cambridge Univ. Press, Cambridge

Maynard Smith J. 1982: Evolution and the Theory of Games. Cambridge Univ. Press

Maynard Sminth J. 1984: The ecology of sex. In Krebs J.R. \& Davies N.B. (eds) Behavioural ecology. Blackwell Scientific Pub., Oxford, pp. 20-221 
Maynard Sminth J. 1986: Contemplating life without sex. Nature 324, 300-301

Maynard Smith J. \& Price G.R. 1973: The logic of animal conflict. Nature 246, 15-18

Muller H.J. 1932: Some genetic aspects of sex. Am. Nat. 64, 118-138

Muller H.J. 1964: The relation of recombination to mutational advance. Mut. Res. 1, 2-9

Newton C. \& Dixon A.F.G. 1987: Cost of sex in aphids: Size of males at birth and the primary sex ratio in Sitobion avenae (F.). Funct. Ecol. 1, 321-326

Normark B.B. 1999: Evolution in a putative ancient asexual aphid lineage: recombination and rapid karyotype change. Evolution 53, 1458-1469

Orgel L.E. \& Crick F.H.C. 1980: Selfish DNA: the ultimate parasite. Nature 284, 604-607

Otto S.P. \& Feldman M.W. 1997: Deleterious mutations, variable epistatic interactions, and the evolution of recombination. Theor. Popul. Biol. 51, 134-147

Palmer J.D., Adams K.L., Cho Y., Parkinson C.L., Qui Y.-L. \& Song K. 2000: Dynamic evolution of plant mitochondrial genomes: mobile genes and introns and highly variable mutation rates. Proc. Natl. Acad. Sci. USA 97, 6960-6966

Parker G.A. 1970a: Sperm competition and its evolutionary effect on copula duration in the fly Scatophaga stercoraria. J. Insect Physiol. 16, 1301-1328

Parker G.A. 1970b: The reproductive behaviour and the nature of sexual selection in Scatophaga stercoraria L. (Diptera: Scatophagidae). II. The fertilization rate and the spatial and temporal relationships of each sex around the site of mating and oviposition. J. Anim. Ecol. 39, 205-228

Parker G.A. \& Stuart R.A. 1976: Animal behaviour as a strategy optimizer. Am. Nat. 110, 1055-1076

Parker G.A. \& Simmons L.W. 1991: A model of constant random sperm displacement during mating: evidence from Scatophaga. Proc. R. Soc. Lond. B 246,107-115

Parker G.A. \& Simmons L.W. 1994: Evolution of phenotypic optima and copula duration in dungflies. Nature 370, 53-56

Parker G.A., Simmons L.W. \& Kirk H. 1990: Analysing sperm competition data. Behav. Ecol. Sociobiol. 27, 55-65

Parker G.A., Simmons L.W., Stockley P., McChristie D.M. \& Charnov E.L. 1999: Optimal copula duration in yellow dung flies: effects of female size and egg content. Anim. Behav. 57, 795-805

Pettersson J. 1968: Preliminary report on ethological observations of the copulatory act among Schizaphis dubia Huc. and Schizaphis borealis Tambs-Lyche (Hom. Aph.). Opuscula Entomologica 33, 359-361 
Pickett J.A., Wadhams L.J., Woodcock C.M. \& Hardie J. 1992: The chemical ecology of aphids. Annu. Rev. Entomol. 37, 67-90

Rispe C., Bonhomme J., Simon J.-C. 1999: Extreme life-cycle and sex ratio variation among sexually produced clones of the aphid Rhopalosiphum padi (Homoptera: Aphididae). Oikos 86, 254-264

Schön I., Butlin R.K., Griffiths H.I. \& Martens K. 1998: Slow molecular evolution in an ancient asexual ostracod. Proc. R. Soc. Lond. B 265, 235-242

Schön I., Gandolfi A., Masso E. di, Rossi V., Griffiths H.I., Martens K. \& Butlin R.K. 2000: Persistence of asexuality through mixed reproduction in Eucypris virens (Crustacea, Ostracoda). Heredity 84, 161-169

Shapiro J.A. 1999: Transposable elements as the key to 21 st century view of evolution. Genetica 107, 171-179

Simmons L.W. \& Siva-Jothy M.T. 1998: Sperm competition in insects: mechanisms and the potential for selection. In Birkhead T.R. \& Møller A.P. (eds) Sperm competition and sexual selection. Academic Press, San Diego, pp. 341-434

Simmons L.W., Parker G.A. \& Stockley P. 1999: Sperm displacement in the yellow dung fly, Scatophaga stercoraria: an investigation of male and female processes. Am. Nat. 153, 302-314

Sokal R.R. \& Rohlf F.J. 1995: Biometry. W.H. Freeman and Company, New York

Spence J.M. \& Blackman R.L. 1998: Orientation of the 'stretched' univalent X chromosome during the unequal first meiotic division in male aphids. Chomosome Research 6, 177181

Stearns S.C. 1987: Why sex evolved and the difference it makes. In Stearns S.C. (ed) The evolution of sex and its consequences. Birkhäuser, Basel, pp. 15-31

Trivers R. 1985: Social Evolution. Benjamin/Cummings, Melno Park, CA

Trivers R.L. \& Willard D.E. 1973: Natural selection of parental ability to vary the sex ratio of offspring. Science 179, 90-92

Turgeon J. \& Hebert P.D.N. 1994: Evolutionary interactions between sexual and all-female taxa of Cyprinotus (Ostracoda: Cyprididae). Evolution 48, 1855-1865

Turgeon J. \& Hebert P.D.N. 1995: Genetic characterization of breeding systems, ploidy levels and species boundaries in Cypricercus (Ostracoda). Heredity 75, 561-570

Ward S.A. \& Wellings P.W. 1994: Deadlines and delays as factors in aphid sex allocation.

Europ. J. Entomol. 91, 29-36

Wedell N., Gage M.J.G. \& Parker G.A. 2002: Sperm competition, male prudence and sperm- 
limited females. Trends Ecol. Evol. 17, 313-320

West S.A. \& Herre E.A. 1998: Partial local mate competition and the sex ratio: a study on non-pollinating fig wasps. J. Evol. Biol. 11, 531-548

West S.A., Herre E.A. \& Sheldon B.C. 2000: The benefits of allocating sex. Science 290 , 288-290

Williams C.G. 1975: Sex and Evolution. Princeton Univ. Press, Princeton

Wilson D.S. 2001: Evolutionary biology: struggling to escape exclusively individual selection. Q. Rev. Biol. 76, 199-205.

Wilson D.S. \& Dougatkin L.A. 1997: Group selection and assortative interactions. Am. Nat. 149, 336-351.

Woodruff R.C., Thompson J.N. Jr., Barker J.S.F. \& Huai H. 1999: Transposable elements and life history traits. Genetica 107, 261-269

Yamaguchi Y. 1985: Sex ratios of an aphid subject to local mate competition with variable maternal condition. Nature 318, 460-462

Zimmermann U. \& Küppers G. 1983: Cell fusion by electromagnetic waves and its possible relevance for evolution. Naturwissenschaften 70, 568-569

\section{Publications}

Dagg J.L. 2000: Why sex? A parody on the paradox. Oikos 89, 188-190

Dagg J.L. in press: Copula duration and sperm economy in the large thistle aphid Uroleucon cirsii (L.). Europ. J. Entomol.

Dagg J.L. submitted: Marginal value theorem and mate competition in the pine needle aphid Schizolachnus obscurus Börner. Ethology

Dagg J.L. \& Vidal S. in press: Sex ratios and mate guarding in aphids. Proc. 6th Int. Symp. Aphids

Dagg J.L., Vidal S. \& Rispe C. submitted: Kin competition and differential sex ratios in aphids. Behav. Ecol. Sociobiol.

Dagg J.L. submitted: Jumping genes, ancient asexual scandals, and the paradox of sex. Evolution 


\section{Curriculum Vitae}

$\begin{array}{ll}\text { Name } & \text { Joachim Dagg } \\ \text { Geburtstag } & 26.01 .1969 \\ \text { Geburtsort } & \text { Frankfurt am Main } \\ \text { Staatsangehörigkeit } & \text { Deutsch }\end{array}$

\section{Schulische Ausbildung und Sozialdienst}

1975-1980

1980-1989

1989-1990

\section{Akademische Ausbildung}

1990-1997

Aug. 1997 - Juli 1998

Aug. 1998 - Okt. 1999

Okt. 1998 - Okt. 2002

\section{Andere Tätigkeiten}

Mai - Juli. 1997

Aug. 1997 - Juli 1998

Okt. 1999 - Apr. 2000
Grundschule Obere Aar, Taunusstein

Gutenberg-Gymnasium, Wiesbaden

Sozialdienst in London

Biologie-Studium, Freie Universität Berlin

Aufbaustudium angew. Systemwissenschaft, Osnabrück

Visiting student von Prof. A.F.G. Dixon an der University of

East Anglia in Norwich, UK

Promotionsstudium der Biologie, Universität Göttingen,

(Betreuung Prof. Dr. S. Vidal)

Pflege meines krebskranken Vaters im finalen Stadium

Hilfswissenschaftler bei Dr. Stephan Trapp am Institut für

Umweltsystemforschung der Universität Osnabrück

Hilfswissenschaftler in der Arbeitsgruppe von Prof. Stefan

Vidal am Inst. Pflanzenpathologie und Pflanzenschutz der Universität Göttingen. 